\title{
NATURAL GAS ENGINE DRIVEN HEAT PUMP SYSTEM - A CASE STUDY OF AN OFFICE BUILDING
}

\author{
By \\ Farshad Kimiaghalam \\ Bachelor of Applied Science (Mechanical Engineering), K.N.T University of Technology \\ (Iran), 2010 \\ Master of Applied Science (Mechanical Engineering), K.N.T University of Technology \\ (Iran), 2012
}

\author{
A Major Research Project \\ presented to Ryerson University \\ in partial fulfillment of the \\ requirements for the degree of \\ Master of Engineering \\ in the program of \\ Mechanical and Industrial Engineering
}

Toronto, Ontario, Canada, 2019

CFarshad Kimiaghalam, 2019 


\section{Author's Declaration}

I hereby declare that I am the sole author of this MRP. This is a true copy of the MRP, including any required final revisions.

I authorize Ryerson University to lend this MRP to other institutions or individuals for the purpose of scholarly research.

I further authorize Ryerson University to reproduce this MRP by photocopying or by other means, in total or in part, at the request of other institutions or individuals for the purpose of scholarly research.

I understand that my MRP may be made electronically available to the public. 


\title{
Natural Gas Engine Driven Heat Pump System - A Case Study of an Office Building
}

\author{
Farshad Kimiaghalam
}

Master of Engineering, Mechanical and Industrial Engineering, Ryerson University, 2019

\begin{abstract}
An eQUEST model was developed to conduct a study of a natural gas engine driven heat pump (GEHP) for an office building in Woodstock, Ontario. The results were also compared with a rooftop unit to investigate annual potential energy saving using GEHP. The models were also calibrated with regression analysis which was obtained from measured data and validated with respect to ASHRAE Guideline 14-2002. The developed ad validated models were used to predict the performance of these system in different regions of Ontario; Toronto, Ottawa, Windsor and Thunder Bay. The results for five cities were compared in terms of annual energy, GHG and energy cost savings. It was concluded that Thunder Bay has the highest annual energy and GHG saving, while Toronto has the highest annual energy cost saving.
\end{abstract}




\section{Acknowledgements}

This work was made possible through the financial support of Union Gas Ltd. and Enbridge Gas Distribution. I would like to thank NSERC, Ontario Center of Excellence (OCE) and TTCI and their staff.

I would like to thank my supervisor, Dr. Alan S. Fung for his valuable suggestions, helpful support and academic guidance throughout the development of this project. I would also like to thank Dr. Rakesh Kumar, Dr. Bess Juanli Ma, Mr. Altamash Baig, Ms. Anna Wang and Mr. Esa Kerme who provided great aid throughout completing this project. The regression analysis was done by Mr. Altamash Baig and the results are used in the project. The blower door test was done by Ms. Anna Wang during a visit to Woodstock site and the results are applied in the report. 


\section{Table of Contents}

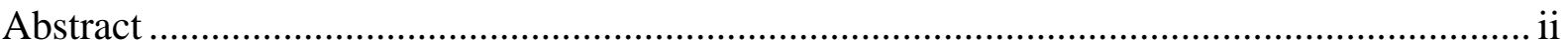

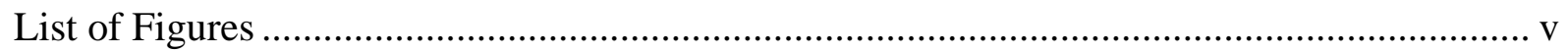

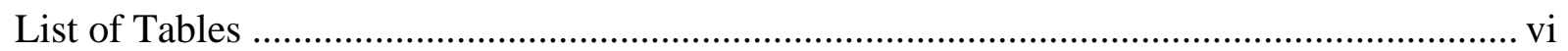

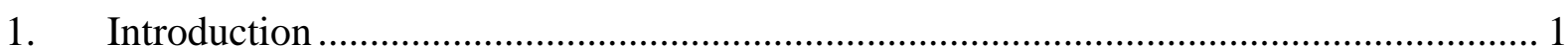

2. Description of GEHPs ................................................................................. 1

3. Review of Studies Conducted on GEHP System ................................................ 2

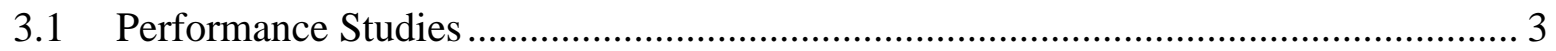

3.2 Evaluation Method for the Performance of GEHP................................................ 4

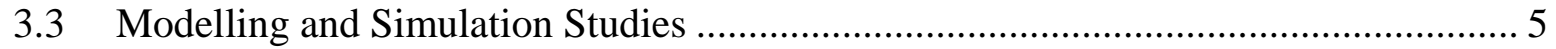

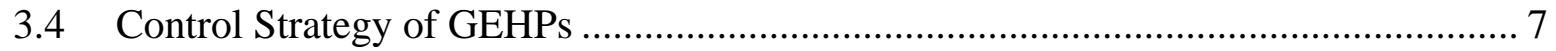

3.5 Variable Refrigerant Flow Heat Pumps.............................................................. 7

4. CASE STUDY: Gas Engine Driven Heat Pump for Office Building in Woodstock ...... 9

5. Building Description and Information ............................................................... 12

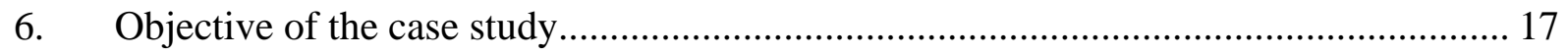

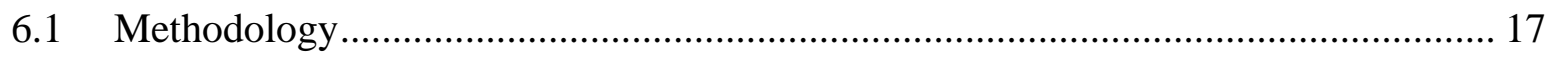

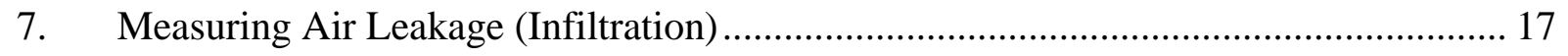

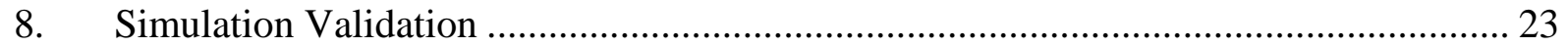

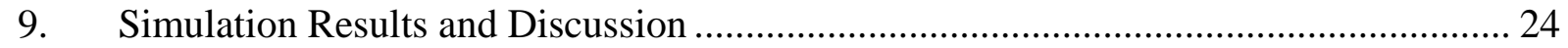

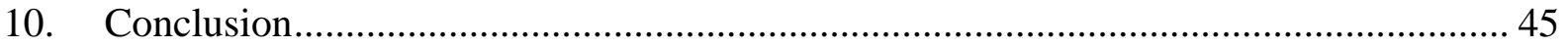

11. Future Work and Potential Problems Faced in this Research Work .......................... 46

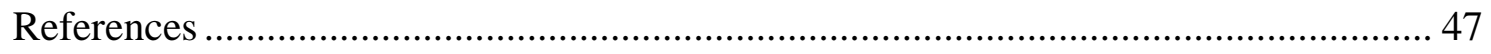




\section{List of Figures}

Figure 1: Schematic diagram of a GEHP cycle in heating and cooling modes [5] ..................... 2

Figure 2: Natural gas fueled internal combustion engine driven heat pump system ................. 10

Figure 3: Schematic diagram of the gas engine driven heat pump's heating and cooling cycle .. 11

Figure 4: The top view and divisions of the Woodstock office building ................................. 13

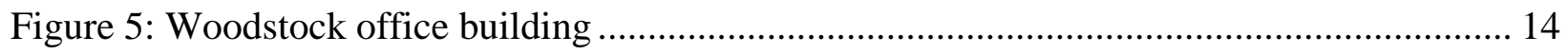

Figure 6: Three-dimensional geometry of the Woodstock office building.............................. 15

Figure 7: Building air-leakage curve obtained during testing ............................................. 18

Figure 8: Air-leakage test (blower door test) .................................................................... 19

Figure 9: Comparison of simulation and regression analysis of monthly variation of RTU gas

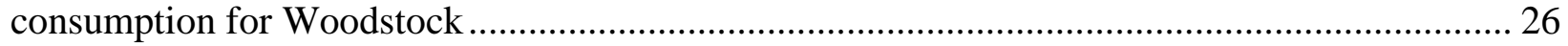

Figure 10: Comparison of simulation and regression analysis of monthly variation of RTU

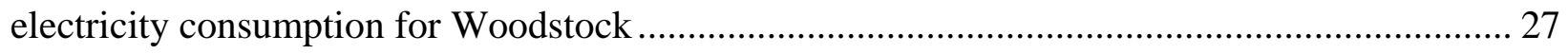

Figure 11: Comparison of simulation and regression analysis of monthly variation of GEHP gas

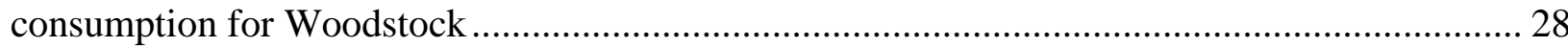

Figure 12.Comparison of simulation and regression analysis of monthly variation of GEHP

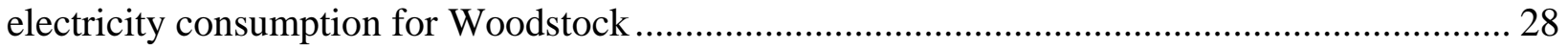

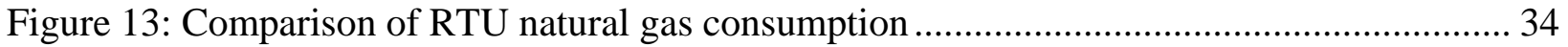

Figure 14: Comparison of RTU electricity consumption .................................................... 34

Figure 15: Comparison of RTU total energy consumption .................................................. 35

Figure 16: Comparison of GEHP natural gas consumption................................................. 35

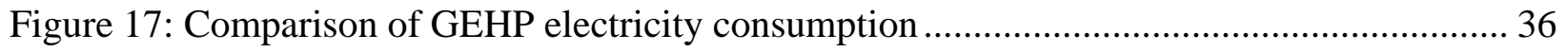

Figure 18: Comparison of GEHP total energy consumption .............................................. 37

Figure 19: Comparison of annual natural gas consumption saving by using GEHP.................. 38

Figure 20: Comparison of annual electricity consumption saving by using GEHP ................... 39

Figure 21: Comparison of annual energy consumption saving by using GEHP ...................... 40

Figure 22: Comparison of annual GHG emission saving ............................................... 41

Figure 23: Total annual cost saving by using GEHP ...................................................... 44 


\section{List of Tables}

Table 1: Summary of the outdoor unit specification ................................................................... 11

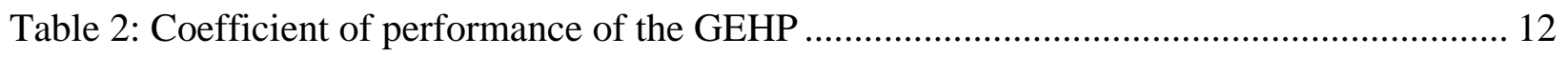

Table 3: Indoor units configuration and capacities ....................................................................... 12

Table 4: Name of each zone in the layout................................................................................. 13

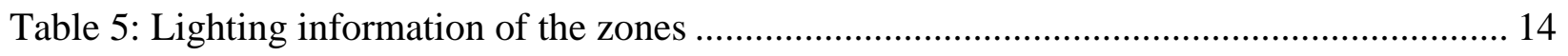

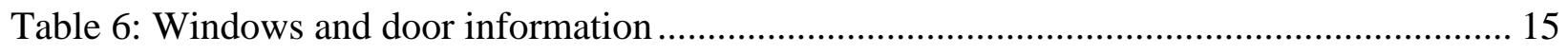

Table 7: Power consuming equipment and their information....................................................... 16

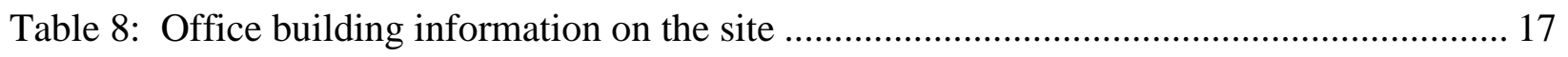

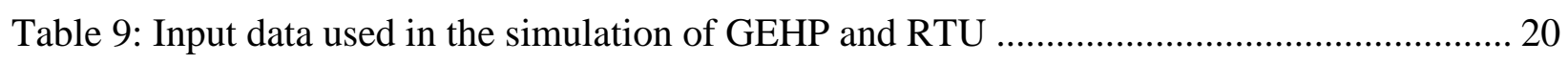

Table 10: Input data used for the simulation of the roof top unit (RTU)..................................... 21

Table 11: Input data used for the simulation of the GEHP system.............................................. 22

Table 12: Monthly plug loads ........................................................................................... 22

Table 13: Range of acceptance of calibration criteria from ASHRAE Guideline 14-2002, for

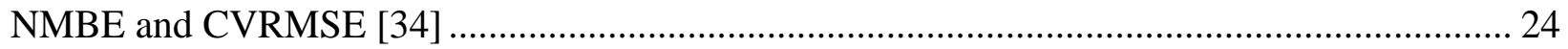

Table 14: GEHP and RTU calibration results obtained from ASHRAE Guideline 14-2002 ....... 24

Table 15: Monthly gas and electricity consumption of GEHP and RTU obtained from regression

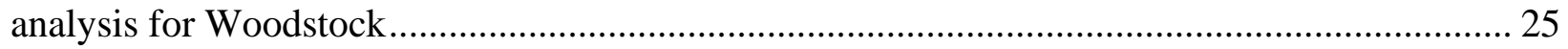

Table 16: Peak heating and cooling loads obtained from eQUEST simulation ........................... 25

Table 17: Simulated monthly gas and electricity consumption of GEHP and RTU for Woodstock

Table 18: Simulated monthly gas and electricity consumption of GEHP and RTU for Windsor 30 Table 19: Simulated monthly gas and electricity consumption of GEHP and RTU for Toronto. 31

Table 20: Simulated monthly gas and electricity consumption of GEHP and RTU for Ottawa .. 32 Table 21: Simulated monthly gas and electricity consumption of GEHP and RTU for Thunder Bay

Table 22. Annual natural gas consumption saving ………....................................................... 38

Table 23. Annual electricity consumption saving....................................................................... 38

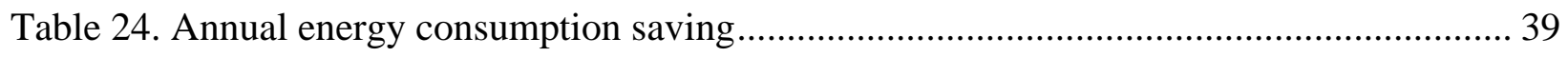

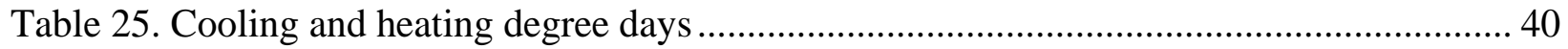

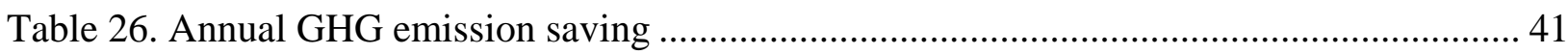


Table 27: Marginal cost of electricity for 2018 based on TOU .............................................. 42

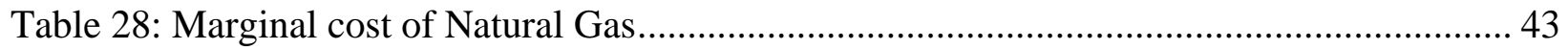

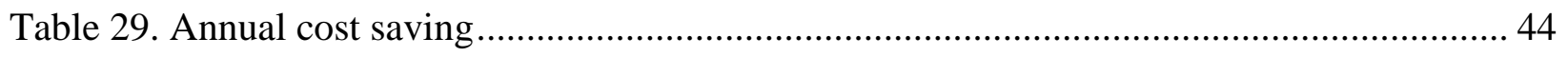




\section{Introduction}

Heat pumps (HPs) are cyclic devices that transfer heat from low temperature medium to high temperature one. In winter time, heat pumps absorb heat from the outdoor environment and transfer it to the building that requires heating whereas in the summer time they reject heat from the building to the outdoor environment. They usually operate on vapor-compression cycle or absorption-compression cycle. Depending on the outdoor sources, heat pumps can be classified as air, water or ground source heat pumps. Based on driving power, they can be categorized as electric driven heat pumps (EHPs), air source heat pump (ASHP), ground source HP, geothermal energy HP, solar assisted HPs or gas engine driven heat pumps [1-3]. Furthermore, air-source heat pumps (ASHPs) can be classified into the electric heat pump the gas engine-driven heat pump (GEHP), and the gas absorption heat pump (GAHP).

In this report, a natural-gas-fueled (ICE engine based) driven heat pump system (GEHP) that delivers heating or cooling energy to the office building in the cold climate (Woodstock, Ontario) is studied.

\section{Description of GEHPs}

A typical heat pump system driven by internal combustion engine (GEHP) consists of the main components indicated in Figure 1. It has reversible vapor compression refrigeration cycle that includes an open compressor, two heat exchangers (evaporator and condenser) inside and outside the building. When the heat pump operates in cooling mode, the indoor and outdoor heat exchangers are evaporator and condenser, respectively [4]. The GEHP system is driven by natural gas fueled internal combustion gas engine instead of an electric motor, the driver for conventional electric heat pumps. The GEHP also has four-way reversing valve. The function of reversing valve is to switch the position of evaporator and condenser in the heating and cooling modes. 


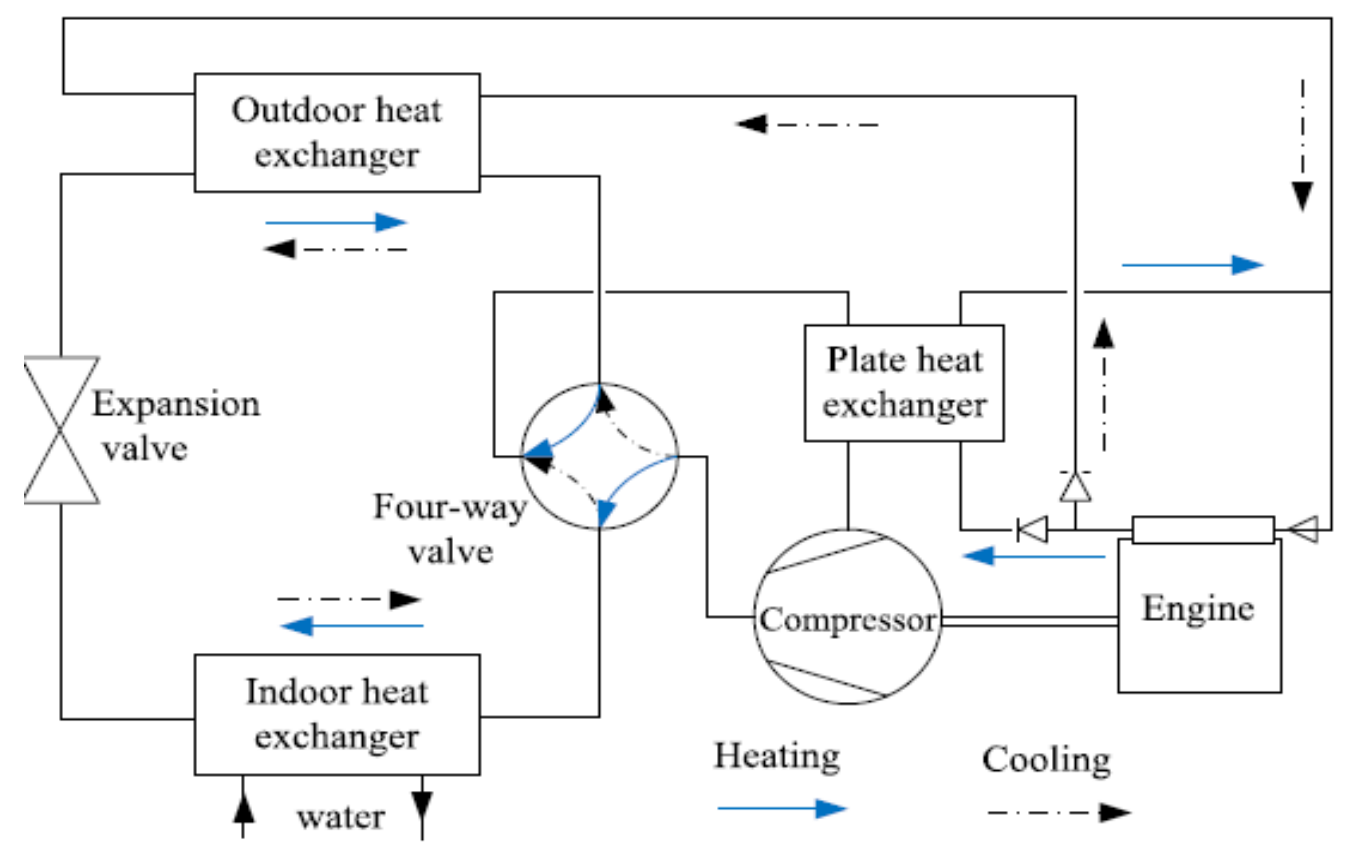

Figure 1: Schematic diagram of a GEHP cycle in heating and cooling modes [5]

\section{Review of Studies Conducted on GEHP System}

In many industrialized countries of the world, coals are burned to extract energy demanded by industry. This burning of coal releases large amount of harmful emissions to the atmosphere. This resulted in the consequence of catastrophic environmental problems. As a result, generation of energy from burning coal is disastrous, subsequently the world has already started to pay more attention to the relatively clean source of energy (such as natural gas) that can reduce environmental pollution as well as consumption of oil and coal. In fact, natural gas has relatively lower level of harmful emissions compared to the other fossil fuels [6]. This is one of the reasons why many investigators have focused on the utilization of natural gas as a primary source of energy in the cyclic device such as gas engine driven heat pump.

The gas engine-driven heat pump (GEHP) is a new energy-efficient heating and air conditioning equipment that utilizes natural gas as the fuel in the gas engine that drives compressor coupled to it [4-7]. The GEHP system is predominantly composed of vapor compression heat pump system that is driven by a gas fueled internal combustion engine, the cold and heat source system, the data acquisition and controlling system. Among the heat pump systems, recently GEHPs have been given more emphasis as a preferable choice in the heating and air-conditioning system [7]. This is due to their notable advantages such as capability to recover about $80 \%$ waste heat from internal 
combustion engine [8], higher primary energy ratio [5], elimination of losses caused by electricity production and transportation [9] and easy modulation of the compressor speed (by adjusting the gas supply) to meet the different load demands [10, 11]. In addition, as the GEHP systems efficiently utilize the natural gas energy with relatively low $\mathrm{CO}_{2}$ emission, they are promising in reducing greenhouse gases, energy-saving and environment protection. Furthermore, running cost of GEHP is lower than conventional electric driven heat pumps [4]. For these reasons, GEHPs have become widespread all over the world. Even though GEHPs are mainly applied for space and water heating/cooling purposes, they can also be utilized in industrial applications, such as drying processes [8, 12].

The main objective of this literature survey is to make a brief review on the studies conducted on GEHP systems with respect to performance, evaluation method for the system performance, modelling and simulation. In addition, studies on heating performance improvement and control strategy of GEHPs will also be briefly assessed.

\subsection{Performance Studies}

Many researchers focused on the performance characteristics and performance improvement of the gas engine driven heat pump system [13-16]. Kamal et al. [13] assessed the field performance of GEHP that provide air-conditioning in a commercial building. They evaluated the performance of four GEHPs by recording the operational data for more than a period of ten months in such a way that the seasonal variations are captured. It was emphasized that the part load operation of IC engine affected the overall COP of the GEHP units significantly. Their study revealed that IC engines driving the GEHPs were oversized compared to the load that was one fourth of the rated full capacity. The result also indicated that operating at such lower loads can reduce the fuel efficiency to one-third of the maximum efficiency. Moreover, Kamal et al. [13] concluded that by operating the engines at full rated capacity, higher performance (COP) can be achieved.

Elgandy et al. [14] developed an experimental test facility to evaluate the performance of GEHP system with heat recovery for heating and cooling application. They investigated the effects of engine speed, ambient air temperature, evaporator water flowrate and the evaporator water inlet temperature on the performance characteristics of the GEHP. The studied performance characteristics were cooling capacity, heating capacity and primary energy ratio (PER). The result of their study showed that increasing evaporator water inlet temperature from $12.2^{\circ} \mathrm{C}$ to $23^{\circ} \mathrm{C}$, 
cooling capacity, heat recovery and PER increased by $18 \%, 31 \%$ and $22 \%$, respectively. When the engine speed was increased from $1200 \mathrm{rpm}$ to $1750 \mathrm{rpm}$, cooling capacity and heat recovery were increased by about $35 \%$ and $28 \%$, respectively, while PER was reduced by $15 \%$. Additionally, it was found that the system performance was affected more significantly by evaporator water inlet temperature than by ambient air temperature and evaporator water flow rate. Another similar experimental study of GEHP for the cooling mode without heat recovery was investigated by Elgandy et. al [15]. The effect of important parameters on the performance of gas engine driven heat pump was studied. The study result showed that the primary energy ratio of the system increased by $22.5 \%$ when the evaporator water inlet temperature was varied from $13^{\circ} \mathrm{C}$ to $24^{\circ} \mathrm{C}$. Moreover, increasing the engine speed from $1300 \mathrm{rpm}$ to $1750 \mathrm{rpm}$ led to the reduction of the system primary energy ratio by $13 \%$.

Load characteristic of a gas engine is one of the factors that can highly affect the overall performance characteristics of the GEHP system. In this regard, Liu et al. [16] conducted experimental research on the performance characteristics of both gas engine and GEHP system for the heating mode over a wide range of operating conditions. They concluded that increasing engine speed resulted in the reduction of both coefficient of performance (COP) and primary energy ratio (PER) of the GEHP system. In their study, Liu et al. [16] found that when the engine speed was remained constant with increasing engine heating load, the output efficiency of the gas engine was increased. They emphasized that it is important to keep the gas engine operating at high load for high output efficiency. Furthermore, from their experimental result, Liu et al. [16] obtained that the hot water temperature of heat recovery can reach $40^{\circ} \mathrm{C}$ to $60^{\circ} \mathrm{C}$, and the energy of heat recovery accounted for about $30 \%-45 \%$ of the total heating capacity of the system.

These revealed that GEHP performance is highly affected by the engine operating condition. The performance characteristic is also affected by the parameters such as ambient air temperature, evaporator water flowrate and evaporator water inlet temperature for cooling mode. Adding heat recovery to the GEHP system improves the performance of the GEHP.

\subsection{Evaluation Method for the Performance of GEHP}

Another important research subject of GEHP is the evaluation method for the system performance. Up to now the two performance evaluation methods mostly used by many researchers are primary energy ratio (PER) $[14,15,17,18]$ and seasonal primary energy ratio 
(SPER) [19]. It is possible to use SPER method for the evaluation of the gas engine heat pump systems utilized for water heating. However, SPER method is very complex in procedure to use [19]. As a result, Zhang et al. [19] presented a new and better evaluation method called integrated primary energy ratio (IPER) based on the PER and SPER methods. To examine the validity of the method, a gas engine driven heat pump water heater (GEHPWH) system under working condition of summer was designed and experimental investigation was carried out by Zhang et al. [19]. Seasonal performance of GEHPWH was estimated. The result of this study showed that the IPER method is more accurate, convenient and simpler to evaluate the performance of GEHPWH than SPER method.

Based on the theoretical and experimental research results stated above, though the recent and the mostly used performance evaluation method for the GEHP system is PER, yet this method is failed to assess the seasonal performance of the gas engine driven heat pump water heater (GEHPWH) system. Hence, the best and suitable seasonal performance evaluation method for the GEHPWH system is IPER method.

\subsection{Modelling and Simulation Studies}

Another crucial research areas of GEHP system are modeling and simulation. Many studies have been conducted on modeling and simulation of GEHP. The first modeling study on GEHP was conducted by MacArthur et al. [20]. They performed a dynamic model of vapor compression HP with a detailed mathematical treatment of condenser, evaporator and accumulator. A lumpedparameter model was developed for the compressor, expansion device and natural-gas-fueled internal combustion. A model of an GEHP, comprising of an engine and a heat pump model together was established by Rusk et al. [21]. The energy costs of operating GEHP and an electricmotor-driven heat pump were modeled as operating in constant-speed and variable-speed modes. The result showed that constant-speed operation was more economical for GEHP while the variable-speed operation was more economical for electric driven heat pumps. Though this model was comparatively consistent, the heat recovery being crucial for GEHP was not taken into consideration.

Modeling of the vapor compression heat pump systems can be categorized as steady state and dynamic simulations [22]. Zhang et al. [23] developed a steady state, semi-empirical model of an

engine driven air to water heat pump by using experimental and manufacturer's data of the main 
components of system. The performance of the GEHP was examined under different operating conditions of the system. The result of the study showed that both heat pump and engine system were significantly affected by engine speed, and GEHP is more energy efficient when it is at low speed mode. In addition, the waste heat of the gas engine can take about $30 \%$ of the total heating capacity in the rated operating condition [23].

$\mathrm{Hu}$ et al. [24] presented thermal modeling and simulation of GEHP system in a variable condition with waste heat recovery. The result of their study indicated that the system performance was remarkably affected by outdoor air temperature and engine speed. For the increasing of engine speed from 1400rpm to 2000rpm, the PER was reduced by $17.6 \%$ while the heat capacity was improved by $26.9 \%$. Reducing the outdoor air temperature from $10^{\circ} \mathrm{C}$ to $2^{\circ} \mathrm{C}$ resulted in dropping of heat capacity and PER by $14.6 \%$ and $11.8 \%$, respectively. For the same outdoor air temperature range, the heat recovery was increased by about $12 \%$. Furthermore, Hu et al. [24] validated the developed simulation model by experimental test. The percentage difference between modeling results and the experimentally measured values were $4.8 \%, 4.6 \%, 6.7 \%$ for heating capacity, PER and waste heat recovery, respectively.

Yang et al. [25] established thermal modeling of GEHP system that works as water heater in winter. They studied the performance variation with hot water temperature, water flow rate and engine speed. The result indicated that increasing of hot water temperature and engine speed led to the reduction of COP and PER, while the performance was enhanced with the rise of water flowrate. However, the heating capacity was improved with the increment of the engine speed and water flowrate but reduced with the increment of the hot water temperature. Moreover, experimental data was used to validate the reliability of the model, and it was reported that the results of the simulation were in good agreement with experimental data. Elgendy et al. [26] presented detailed modeling of a GEHP with working fluid R410A for cooling applications. This model was developed to simulate the performance of GEHP characterized by PER, cooling capacity and gas engine energy consumption. It was reported that the model accuracy to predict the system cooling capacity, energy consumption and primary energy ratio was about $7 \%, 5 \%$ and $6 \%$, respectively.

The above studies are few of the many investigations made on modeling and simulation GEHP. But these studies are highly related and relevant to the GEHP system considered in this report and as a result, they will be helpful during further studies of the GEHP system considered in this report. 


\subsection{Control Strategy of GEHPs}

Some studies focused on the control strategies for the GEHP since improving control strategy (optimum control) increases efficiency of GEHP [8] and decreases consumption of energy. Li et al. [27] proposed a cascade fuzzy control algorithm as a control strategy for the GEHP system. It controls the return water temperature and engine speed via its outer loop and inner loop respectively. In their study, they proved that as compared to the performance of the common control for the heat pump system, PI (proportional and integral) control strategy, the cascade fuzzy control provides better performance, smaller overshoot temperature and reduced reaction time. Yang et al. [28] developed an intelligent control scheme for GEHP system to investigate the dynamic characteristics of the system in the heating operation. In their study, a model that consists of the main components of the GEHP was made to test the effect of the intelligent control scheme. The result of the study showed that the model was very successful in analyzing the effects of the control system. Furthermore, the steady state accuracy of the intelligent control scheme was higher than that of the fuzzy controller. Shin et al. [29] established dynamic modeling of the GEHP in a cooling mode to simulate the dynamics of GEHP for the design of control algorithm. It was found that the time variation of the simulated temperatures, pressures and COP was close to the real systems, and this indicated that the model can be served as a virtual GEHP system to test many algorithm candidates.

These studies revealed that the three control strategies for the GEHP system are the PI (proportional and integral), cascade fuzzy control and intelligent control schemes. Of these, the intelligent control scheme provides the best accuracy of control strategy of the GEHP system.

\subsection{Variable Refrigerant Flow Heat Pumps}

Variable Refrigerant Flow (VRF) system is an air conditioning system that varies the refrigerant flow rate with the help of the variable speed compressor and electronic expansion valves to meet the space heating/cooling load in such a way that the zone air temperature is maintained at the set temperature. In VRF system, a single outdoor unit (or multiple units) can be connected to multiple indoor fan coil units of varying capacity and configuration throughout the building and the refrigerant is used as the heating and cooling medium. 
GEHP system with VRF system has a reversible cycle; and hence provides cooling or heating based on season. For such mode of operation, the VRF system has a four-way valve located in the outdoor unit. The four way-valve reverses the refrigerant path so that the variable refrigerant flow system can provide both cooling and/or heating based on season. Because of this feature, the GEHP systems with VRF system can provide cooling and heating through a common pipe network and one outdoor unit.

The outdoor unit has one or more compressors that are inverter driven, and hence the speed of the compressor can be varied by changing the frequency of the power supply to the compressor. The amount of refrigerant delivered by the compressor is varied by changing the compressor speed. A peculiar feature of VRF systems is that they regulate cooling/heating output by modulating the refrigerant flow continuously with the variable speed compressor [30]. The refrigerant is heated/cooled by an outdoor unit and circulated within the building to multiple indoor fan coil units. When an indoor unit sends its cooling/heating demand to the outdoor unit, the outdoor unit provides the amount of refrigerant required to satisfy the individual requirements of each indoor unit.

VRF systems mainly consist of one or more outdoor units and multiple indoor units. An outdoor unit is composed of one or more compressors (one of which is an inverter-driven variable speed compressor). The indoor unit has electronic expansion valve(s), direct expansion coils, and fans. The outdoor and indoor units are connected by relatively long refrigerant line and manipulated by controllers.

Various studies have been conducted on variable refrigerant flow systems. Zhu et al. [31] developed a simulation model for the variable air flow (VAF) air conditioning system combined with an outdoor air processing unit in heating mode. The developed simulation models were validated using the experimental data reported in literatures. It was found that the accuracy of the developed simulation model in predicting daily heating capacity, energy consumption and COP were about $7.87 \%, 12.45 \%, 6.19 \%$, respectively. Aynur et al. [32] performed simulation evaluation and comparison study of VRF and variable air volume (VAV) air conditioning systems for an existing office building under the same outdoor conditions and internal load profiles for the whole cooling season. Their study revealed that as compared to the VAV air-conditioning system, the VRF air conditioning system assured 27.1-57.9\% energy-saving potentials based the system configuration, indoor and outdoor conditions. 
Liu et al. [30] performed simulation of VRF and ground source heat pump (GSHP) system using EnergyPro and eQUEST software, respectively. In their studies, Liu et al. [30] conducted a comparison of energy efficiency between the air-source VRF and GSHP systems. The simulation results indicated that for conditioning the same small office building, GSHP system is more energy efficient than the air-source VRF system. Furthermore, Liu et al. [30] found that for the two locations in US representing hot and cold climates, GSHP system saves 9.4-24.1\% of HVAC energy compared with the "heat recovery" type VRF system.

Based on the above studies, it can be concluded that the GEHP systems with VRF system that uses one external unit connected to several indoor units are popular as they can provide both cooling and heating using the same system. In addition, because of their reduced space requirement (the same outdoor unit and piping network is used), they can quickly replace conventional central air conditioning system.

\section{CASE STUDY: Gas Engine Driven Heat Pump for Office Building in Woodstock}

The GEHP system considered in this case study consists of natural-gas-fueled (ICE engine based) driven heat pump system that delivers heat energy to the office building, Woodstock, Ontario. It is similar to variable refrigerant flow (VRF) system. Some VRF systems have an option for heat recovery to utilize heat rejected from cooling zones to heating zones. However, the GEHP considered in this case study has heat recovery from engine to assist heat transfer from the outdoor evaporator coil to enhance the heating performance. Figure 2 shows the GEHP system considered in this case study. The studied system can provide either heating or cooling, depending on season. The GEHP system has two basic unit configurations: outdoor unit and indoor unit configuration as can be seen in Figure 3. 


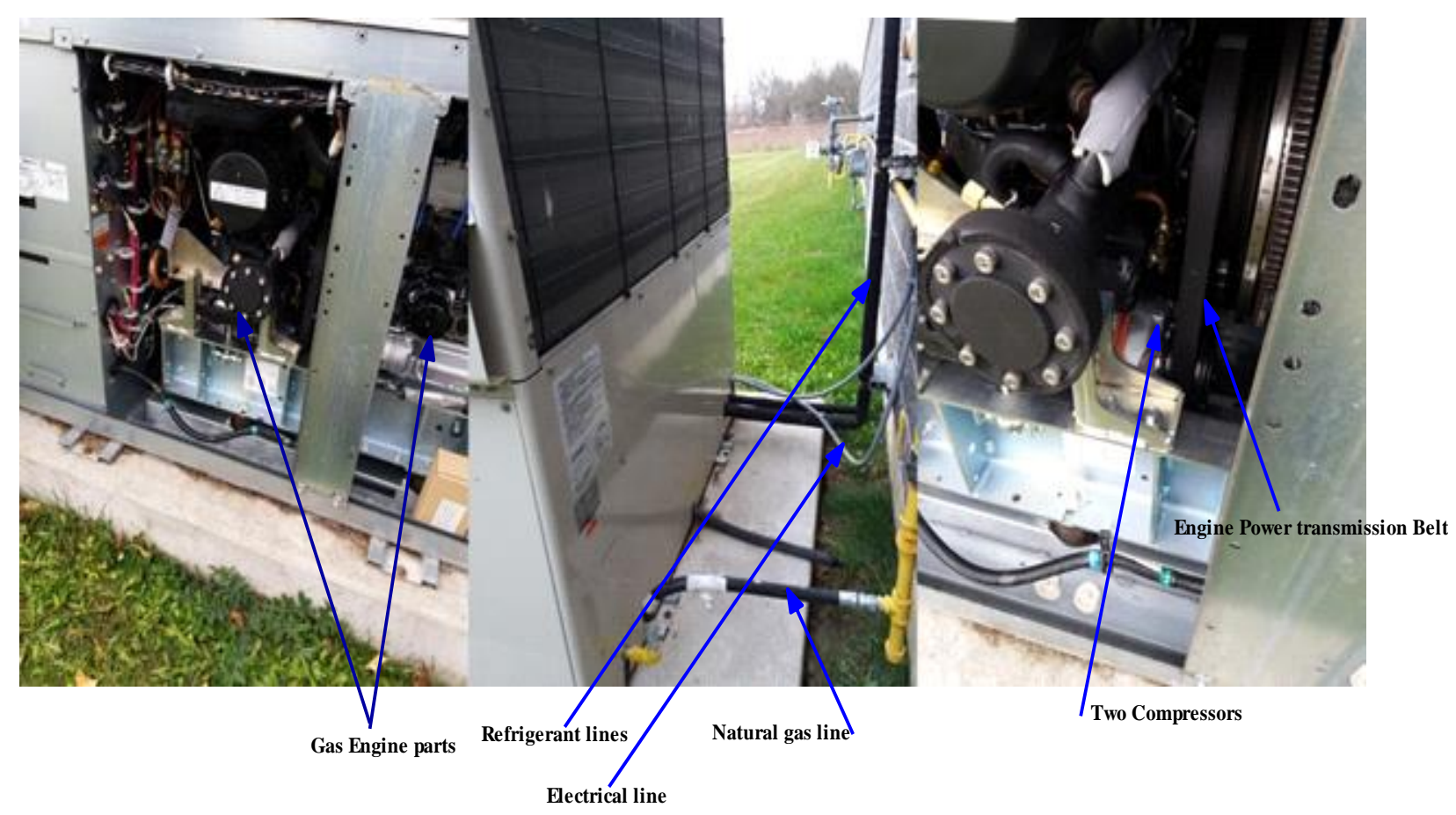

Figure 2: Natural gas fueled internal combustion engine driven heat pump system

\section{(i) Outdoor Unit}

The GEHP system considered in this case study is a multi-split variable refrigerant flow (VRF) system in which the refrigerant is used as the heating or cooling medium. The gas engine drives the compressors utilizing natural gas as the fuel. The outdoor unit consists of two compressors (one with variable speed), a heat exchanger and a four-way valve.

Some VRF systems have inverter driven variable speed compressors that enable them to have a wide capacity modulation with high part-load efficiency [33]. For such system, by changing the frequency of the inverter, the outdoor unit varies its capacity by varying the discharged refrigerant mass flowrate so as to meet the desired heating or cooling loads of the various zones. In this way, the fluctuating heating or cooling load requirements of different zones are met by variable refrigerant flow system. The GEHP considered in this case study is YNCP560J model, Yanmar's product. It has overall cooling and heating capacity of $56 \mathrm{~kW}$ and $63 \mathrm{~kW}$, respectively as indicated in Table 1. 


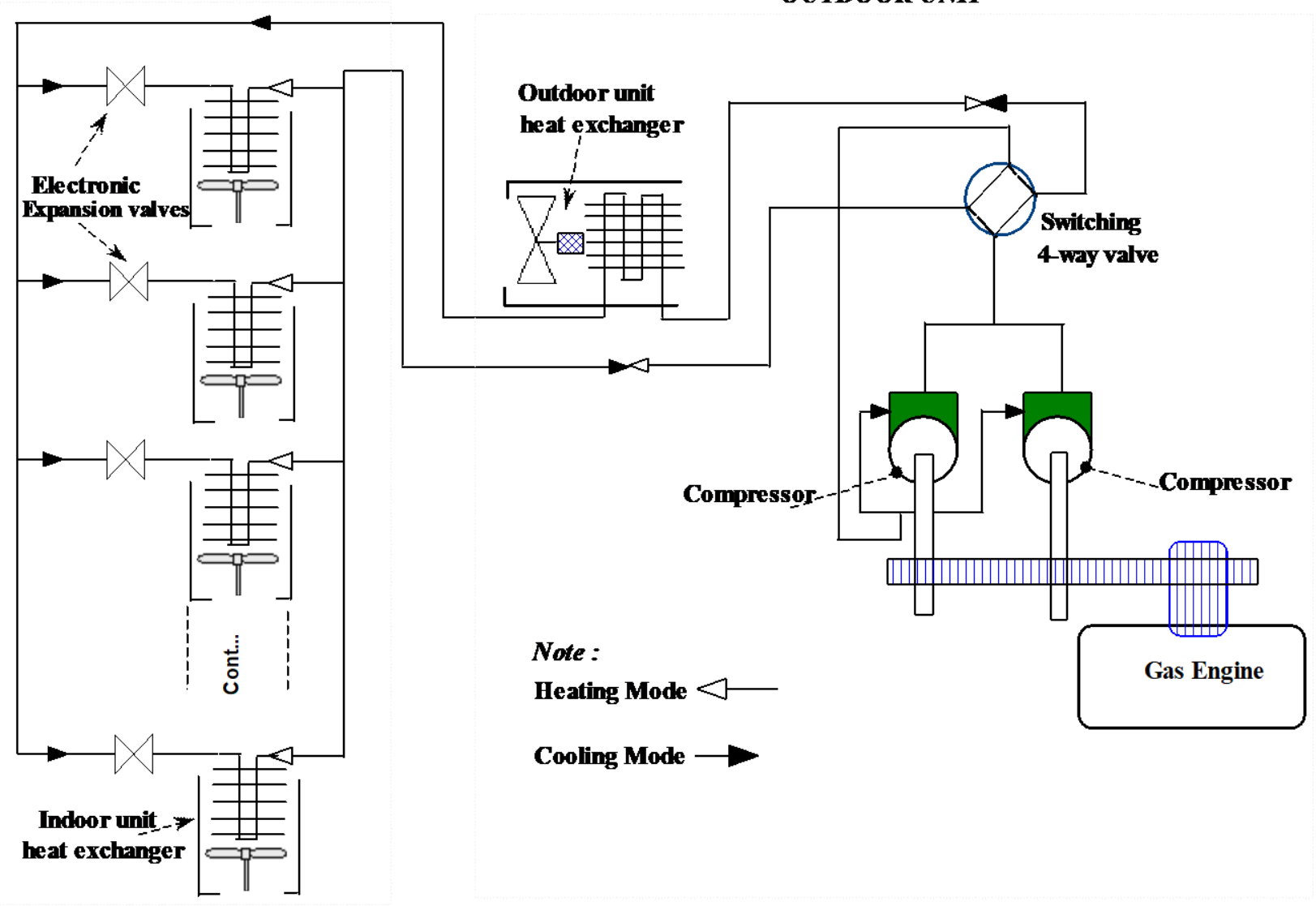

Figure 3: Schematic diagram of the gas engine driven heat pump's heating and cooling cycle (one outdoor unit is connected to 14 indoor units)

Table 1: Summary of the outdoor unit specification

\begin{tabular}{|c|c|}
\hline \multicolumn{2}{|c|}{$\begin{array}{l}\text { GEHP Model Name: YNCP560J } \\
\text { Product Name: YNCP560J-NB } \\
\text { Manufacture: Yanmar Energy System Co. Ltd. }\end{array}$} \\
\hline Rated Cooling Capacity & $56 \mathrm{~kW}$ \\
\hline Rated Heating Capacity & $63 \mathrm{~kW}$ \\
\hline Fuel Type & Natural Gas \\
\hline Power Supply & Single Phase \\
\hline Power Supply Frequency & $\mathrm{AC} 200 \mathrm{~V}$ \\
\hline Fuel Consumption Rate (HHV) & For Cooling: 43.3kW, For Heating: 41kW \\
\hline Rated Power Consumption & For Cooling: $0.98 \mathrm{~kW}$, For Heating: $0.91 \mathrm{~kW}$ \\
\hline Refrigerant & $\mathrm{R} 410 \mathrm{~A}$ \\
\hline Design Pressure & $\mathrm{H} 4 / \mathrm{L} 2.2 \mathrm{MPa}$ \\
\hline Air Tight Test Pressure & $\mathrm{H} 4 / \mathrm{L} 2.2 \mathrm{MPa}$ \\
\hline
\end{tabular}


Table 2: Coefficient of performance of the GEHP

\begin{tabular}{|l|l|}
\hline \multicolumn{2}{|c|}{ COP $=\frac{1}{(\text { Gas Consumption }(H H V))}$} \\
\hline COP $_{\text {cooling }}$ & $56 /(43.3)=1.3$ \\
\hline COPheating & $63 /(41)=1.5$ \\
\hline
\end{tabular}

(ii) Indoor Unit

The indoor unit of the VRF system under consideration consists of heat exchangers, expansion valves, temperature sensors and fans. Many indoor units are connected to a single outdoor unit. In our GEHP system, 14 indoor units are connected to one outdoor unit. The indoor units of the system under consideration have different configurations and capacities as shown in the Table 3.

Table 3: Indoor units configuration and capacities

\begin{tabular}{|c|c|c|c|c|}
\hline Configuration & Quantity & $\begin{array}{c}\text { Cooling Capacity of } \\
\text { Each Unit (Tons) }\end{array}$ & $\begin{array}{c}\text { Total Cooling } \\
\text { Capacity (kW) }\end{array}$ & $\begin{array}{c}\text { Heating } \\
\text { Capacity (kW) }\end{array}$ \\
\hline Ceiling Suspended & 1 & 1 & 3.52 & 3.6 \\
\hline Wall Mount & 4 & 0.6 & 8.45 & $4 \times 2.2=8.8$ \\
\hline $\begin{array}{c}\text { 2'x2' 4-Way } \\
\text { Cassette }\end{array}$ & 2 & 1 & 44 & $9 \times 5.6=50.4$ \\
\hline $\begin{array}{c}\text { 2'x2' 4-Way } \\
\text { Cassette } \\
\text { Total }\end{array}$ & 7 & 1.5 & 44 & $9 \times 5.6=50.4$ \\
\hline
\end{tabular}

\section{Building Description and Information}

The building under consideration is an office building with an estimated area of $5413 \mathrm{ft}^{2}$. The building has divisions that includes general office, three meeting rooms, waiting room, lunch room, data and voice room, guest room, equipment and storage room and vestibule room as indicated in Figure 4. Figure 5 is photo of the main entrance of the Woodstock office building, and the name of each zone is indicated in Table 4. Figure 6 shows the 3-dimensional geometry of the modeled office building, obtained after running the eQUEST simulation. Table 5 presents the lighting information which is important for the estimation of the lighting density $\left(\mathrm{W} / \mathrm{ft}^{2}\right)$ of the zones, and 
the lighting density of each zone is one of the input data required in the eQUEST simulation of GEHP and RTU. Furthermore, using the lighting density, plug load density and other data, eQUEST estimates the occupied and unoccupied loads of the office building.

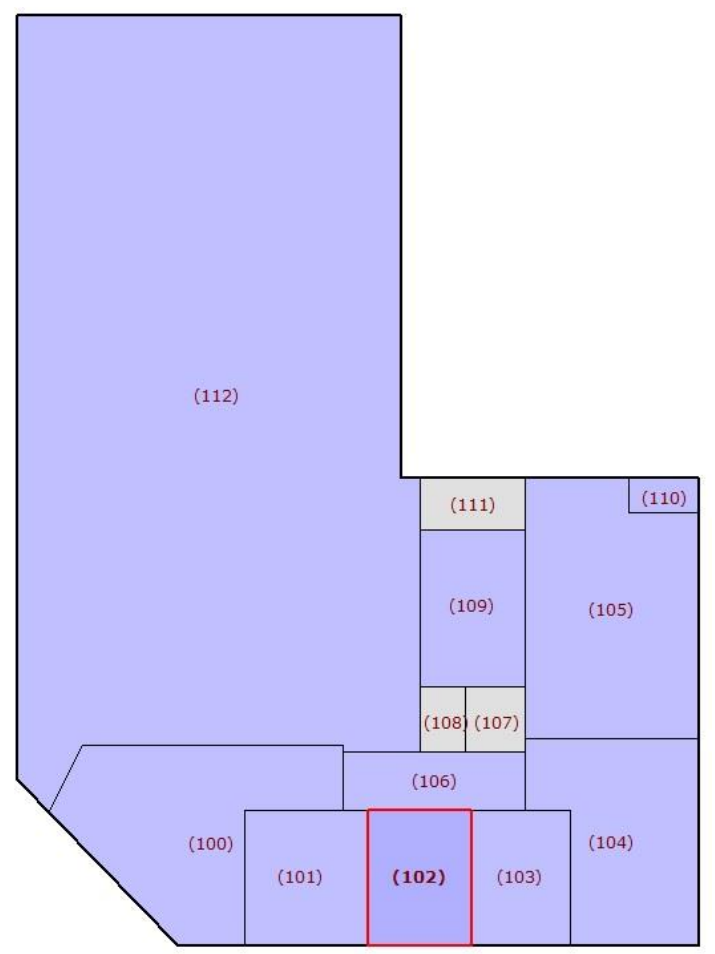

Figure 4: The top view and divisions of the Woodstock office building

Table 4: Name of each zone in the layout

\begin{tabular}{|c|c|c|c|}
\hline Zone Number & Zone Name & Area $\left(\mathbf{f t}^{\mathbf{2}}\right)$ & Indoor Unit \\
\hline 100 & Waiting Room & 403.3 & 1 \\
\hline 101 & Meeting Room & 188.6 & 1 \\
\hline 102 & Meeting Room & 158.4 & 1 \\
\hline 103 & Meeting Room & 149 & 1 \\
\hline 104 & Meeting Room & 336.8 & 2 \\
\hline 105 & Lunch Room & 480.9 & - \\
\hline 106 & Corridor & 120.6 & - \\
\hline 107 & Washroom & 43.1 & 1 \\
\hline 108 & Data \& Voice & 33.1 & - \\
\hline 109 & Equipment \& Storage & 182.9 & - \\
\hline 110 & Vestibule & 26.4 & $\mathbf{1 4}$ \\
\hline 111 & Corridor & 59.7 & 3228.8 \\
\hline 112 & General office & $\mathbf{5 4 1 1 . 6}$ & \\
\hline & Total & & \\
\hline
\end{tabular}




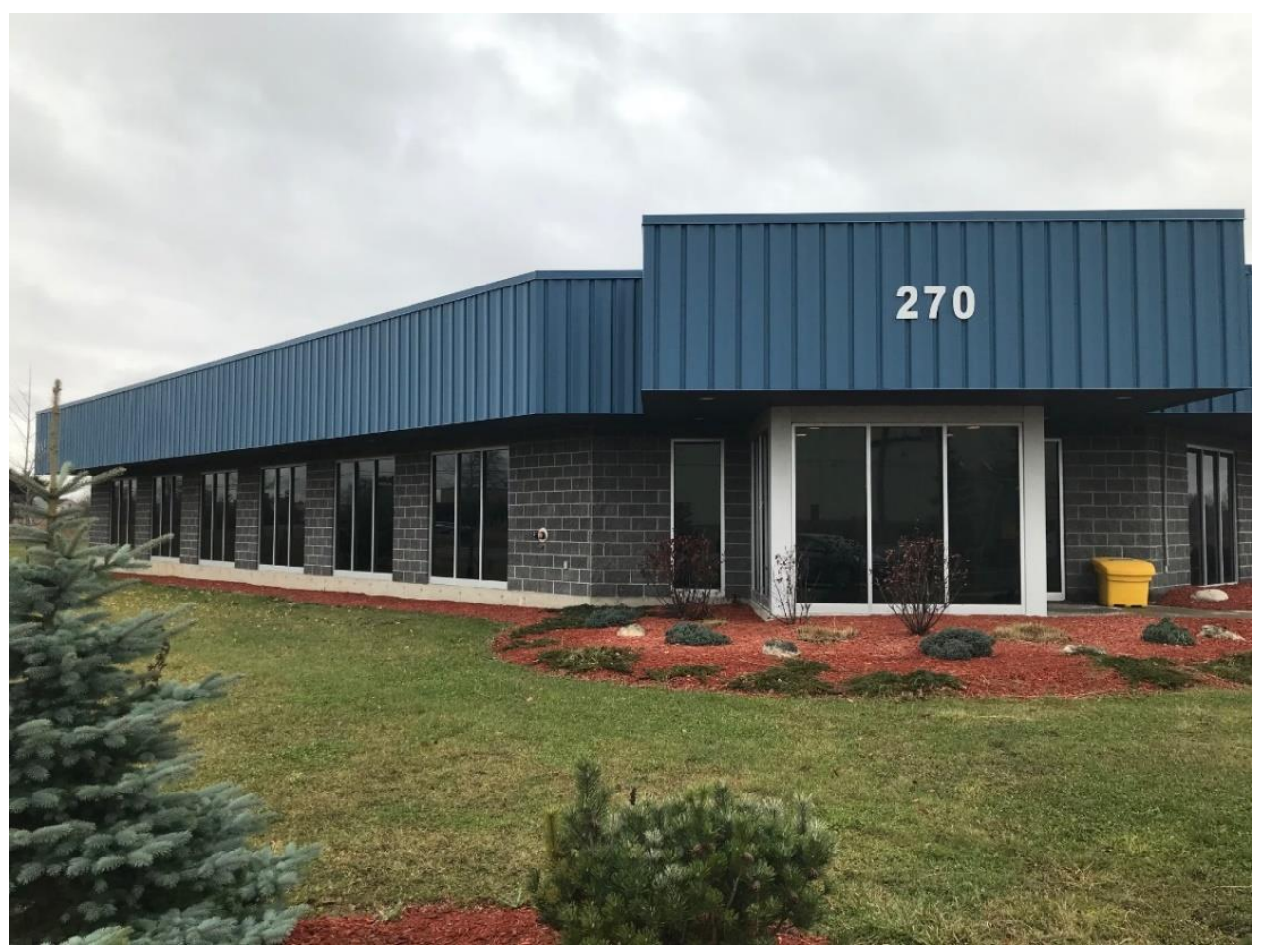

Figure 5: Woodstock office building

Table 5: Lighting information of the zones

\begin{tabular}{|c|c|c|c|c|}
\hline Zone Number & Lighting Components & Quantity & Wattage (W) / Unit & $\begin{array}{c}\text { Total } \\
\text { Wattage }\end{array}$ \\
\hline \multirow{2}{*}{112} & Florescent & 66 & 13 & 858 \\
\hline \multirow{2}{*}{100} & Florescent & 15 & 13 & 195 \\
\hline \multirow{2}{*}{101} & Incandescent light bulb & 4 & 40 & 160 \\
\hline 102 & Florescent & 9 & 13 & 117 \\
\hline 103 & Florescent & 6 & 13 & 78 \\
\hline \multirow{2}{*}{104} & Florescent & 6 & 13 & 78 \\
\hline 105 & Florescent & 12 & 13 & 156 \\
\cline { 2 - 5 } & Incandescent light bulb & 6 & 40 & 130 \\
\hline 110 & Florescent & 10 & 13 & 80 \\
\hline 111 & Incandescent light bulb & 2 & 40 & 26 \\
\hline 109 & Florescent & 2 & 13 & 104 \\
\hline 107 & Florescent & 8 & 13 & 52 \\
\hline
\end{tabular}




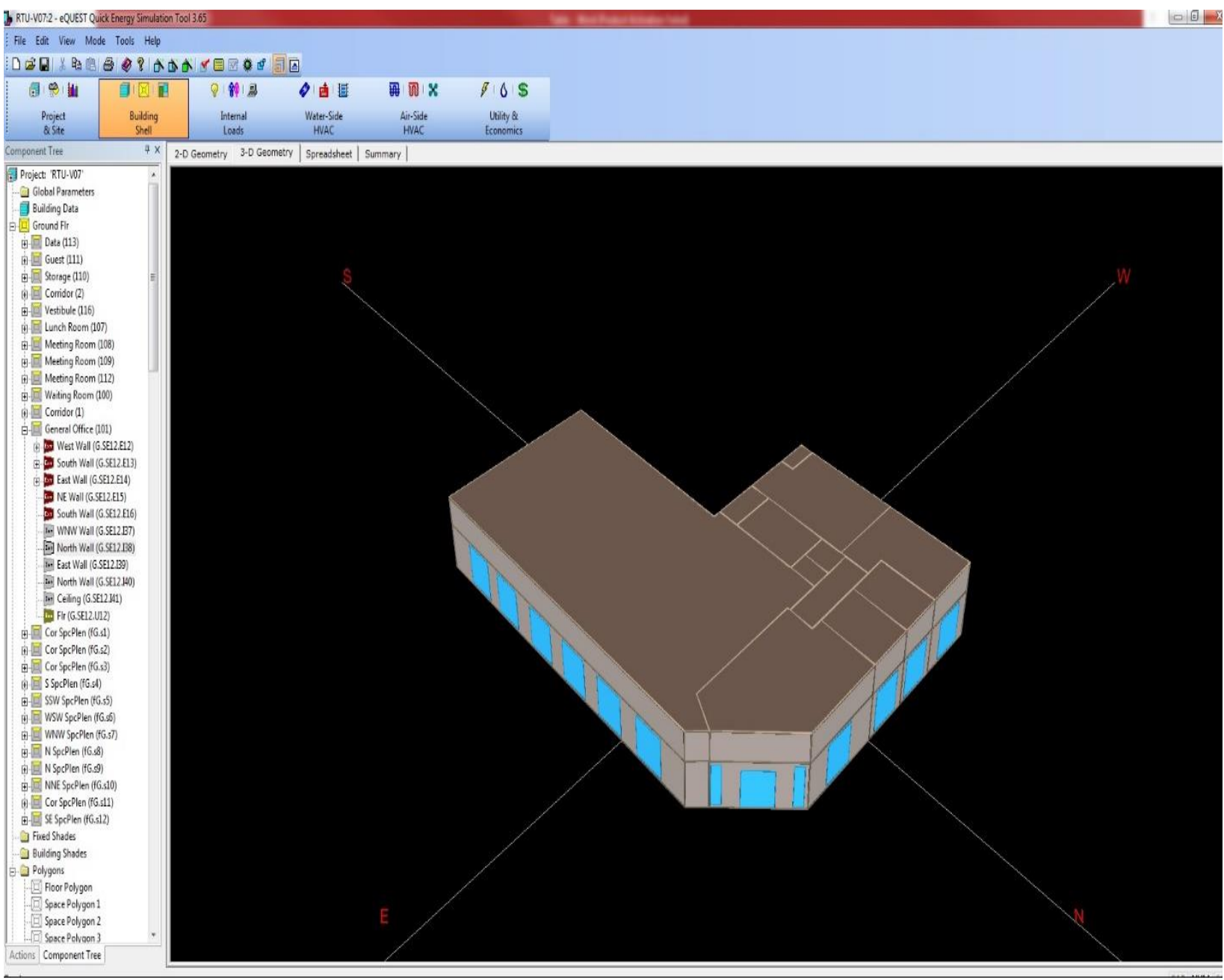

Figure 6: Three-dimensional geometry of the Woodstock office building

Table 6: Windows and door information

\begin{tabular}{|c|c|c|}
\hline Component of the Building & Dimension (ftxft) & Quantity \\
\hline Windows & $7.8 \times 7.87$ & 15 \\
\hline Windows & $2.62 \times 7.87$ & 2 \\
\hline Entrance Door & $6 \times 7$ & 1 \\
\hline Vestibule Door & $3.44 \times 7$ & 1 \\
\hline
\end{tabular}


Table 7: Power consuming equipment and their information

\begin{tabular}{|c|c|c|c|c|}
\hline Area Name & Equipment & Quantity & Specifications & $\begin{array}{l}\text { Wattage } \\
\text { (W)/unit }\end{array}$ \\
\hline Waiting Room & TV & 1 & DAENYX & 80 \\
\hline Meeting Room & Monitor & 1 & Lenovo Thinkvision (24") & 30 \\
\hline Meeting Room & TV & 1 & Sharp & 220 \\
\hline Meeting Room & - & - & - & - \\
\hline \multirow{2}{*}{ Meeting Room } & TV & 1 & Cisco & 228 \\
\hline & Refrigerator & 1 & Danby (DAR026A1 WDD) & 33 \\
\hline \multirow{10}{*}{ Lunch Room } & Refrigerator & 1 & Inglis (DFF091A1WDB) & 440 \\
\hline & $\begin{array}{l}\text { Vending } \\
\text { Machine }\end{array}$ & 1 & Frigidaire (WA62402512) & 380 \\
\hline & $\begin{array}{l}\text { Vending } \\
\text { Machine }\end{array}$ & 1 & $\begin{array}{l}\text { Automatic products } \\
\text { (LCM199120042) }\end{array}$ & 360 \\
\hline & $\begin{array}{l}\text { Vending } \\
\text { Machine }\end{array}$ & 1 & Automatic Products & 360 \\
\hline & Coffee Maker & 1 & Culligan & 420 \\
\hline & Coffee Maker & 1 & JBC (15702573) & 1800 \\
\hline & Microwave & 3 & Panasonic (NN-SG626W) & 1500 \\
\hline & Dish Washer & 1 & Maytag (W10641736A) & 1450 \\
\hline & Toaster & 1 & Black \& Decker & 1100 \\
\hline & Oven Toaster & 1 & Black \& Decker & 1200 \\
\hline Corridor & - & - & - & - \\
\hline WC & - & - & - & - \\
\hline Data \& Voice & - & - & - & - \\
\hline \multirow{2}{*}{$\begin{array}{l}\text { Equipment \& } \\
\text { Storage }\end{array}$} & Printer & 1 & Canon (C3325i) & 1500 \\
\hline & Printer & 1 & HP (Design Jet 500) & 150 \\
\hline Vestibule & - & - & - & - \\
\hline Corridor & - & - & - & - \\
\hline \multirow{12}{*}{ General Office } & TV & 1 & Sharp (AQUOS LC-60E77UN) & 390 \\
\hline & Water Dispenser & 1 & Culligan (19-GU-CUL) & 500 \\
\hline & Printer & 1 & HP (4350n WS4350LJ5) & 790 \\
\hline & Printer & 2 & Canon (F165200) & 120 \\
\hline & Electrical Heater & 1 & Bionaire (BCH9212-CN) & 1500 \\
\hline & Electrical Heater & 1 & Sunbeam (SFH1000-CN) & 1500 \\
\hline & Electrical Heater & 1 & Holmes (HFH441) & 1500 \\
\hline & Monitor & 12 & Lenovo Thinkvision (24") & 30 \\
\hline & Monitor & 6 & Lenovo Thinkvision (18") & 25 \\
\hline & Monitor & 9 & Dell (17”) & 11 \\
\hline & Monitor & 2 & HP (24”) & 23 \\
\hline & $\mathrm{PC}$ & 25 & - & 200 \\
\hline
\end{tabular}




\section{Objective of the case study}

One of the objectives of the case study is to make a base building model for the GEHP as well as the roof top unit (RTU) using eQUEST software. In addition, it is also aimed to calibrate the eQUEST model for both systems so that the baseline design consumption of gas and electricity for both GEHP and RTU can be compared with regression analysis, which was obtained from experimental data.

\subsection{Methodology}

In this study, the eQUEST v3.65 software has been used in combination with the weather data obtained from the nearby weather station close to the Woodstock office and has been converted to bin file using CanMeteo software as eQUEST only accept bin files. In addition, the input data such as the building data (parameters and dimensions), GEHP specifications, RTU specifications, temperature set points, schedules, etc., were utilized as inputs to the models in such a way that the required outputs are generated by eQUEST. The main inputs used in the simulation were: weather data, cooling and heating capacities and Yanmar's manufacturer product specification.

Each of the zones indicated in Figure 4 was modelled as a separate zone in the eQUEST simulations. The model is developed for both cooling and heating seasons during the summer and winter.

Table 8: Office building information on the site

\begin{tabular}{|l|l|}
\hline Type of Site & One Story Office \\
\hline Total Area & $5413 \mathrm{ft}^{2}$ \\
\hline Floor to Ceiling Height & $8.5 \mathrm{ft}$ \\
\hline Occupants & 59 \\
\hline Number of Floor & 1 \\
\hline Energy Sources & Electricity and Natural Gas \\
\hline
\end{tabular}

\section{Measuring Air Leakage (Infiltration)}

It is important to identify and measure the amount of infiltration in a building since the infiltration can have a significant impact on indoor air quality, building energy consumption (heating and cooling loads in buildings). From the standard methods used to measure the infiltration through a building envelope, the fan pressurization method was used in this study. This 
method evaluates the air leakage characteristics from the airflow rate at given indoor-outdoor static pressure differences based on mechanical pressurization or de-pressurization of a building. To conduct the blower door test, two blower door fans were placed in the main entry door to depressurize the building so that the air from the inside of the building is sucked out causing the outside air to be drawn into the building through the leakage points.

The normal procedure was followed and described as: HVAC equipment were switched off before the test and all external doors and windows were closed. The test fans were switched on and the flow through them increased till the pressure differential between indoor and outdoor reaches $50 \mathrm{~Pa}$. The total air flow through the fan and the building pressure differential (inside to outside) were recorded. The fan speed was then slowly reduced in steps with fan flow and pressure difference data were recorded at each step.

The blower door infiltration test was performed based on the above procedure to determine the air change per hour $(\mathrm{ACH})$ of the space, excluding the warehouse. Based on 5 data points, the building leakage curve found that $4311 \mathrm{cfm}$ was the total airflow leakage at differential pressure of $50 \mathrm{~Pa}$ which was equivalent to $6.63 \mathrm{ACH}$ for the given building volume. The building air leakage curve generated from the measurement is as indicated in Figure 7.

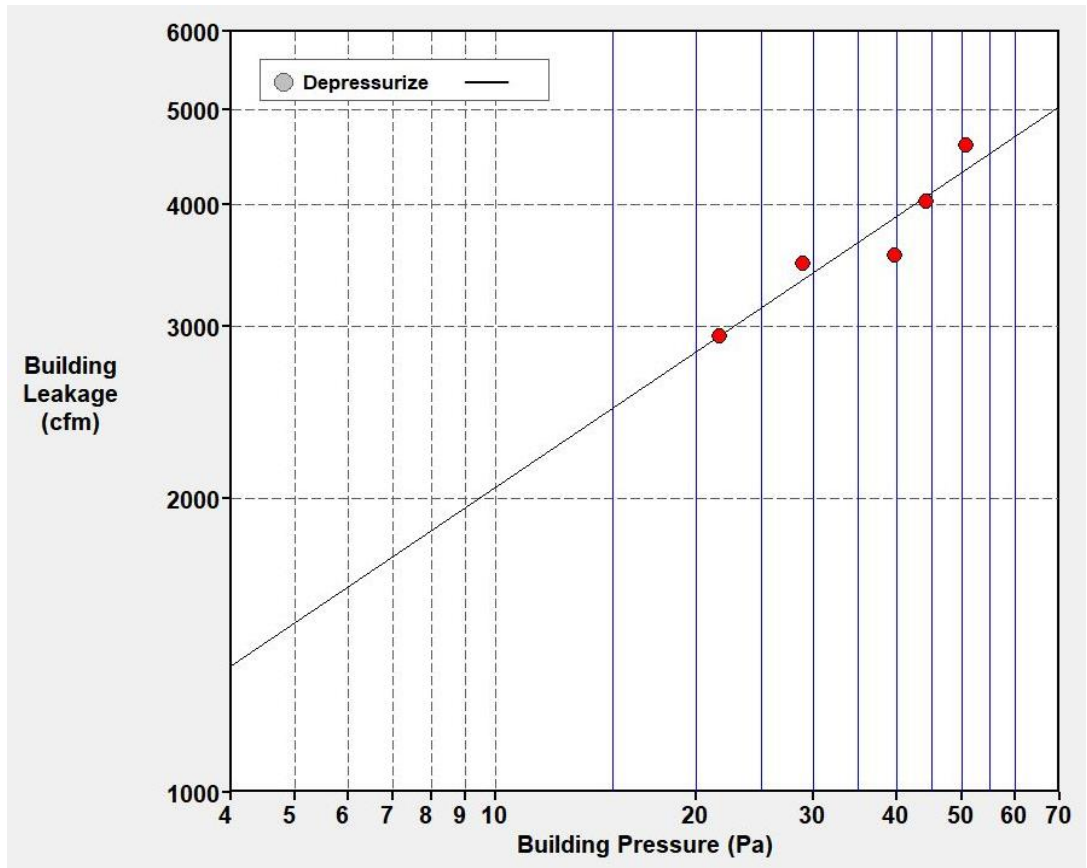

Figure 7: Building air-leakage curve obtained during testing 
Figure 8 shows the blower infiltration test components used in the measurement of the office building air-leakage. It consists of a variable-speed fan, a pressure gauge to measure the pressure differences between inside and outside the building, and an airflow manometer and hoses for measuring airflow.

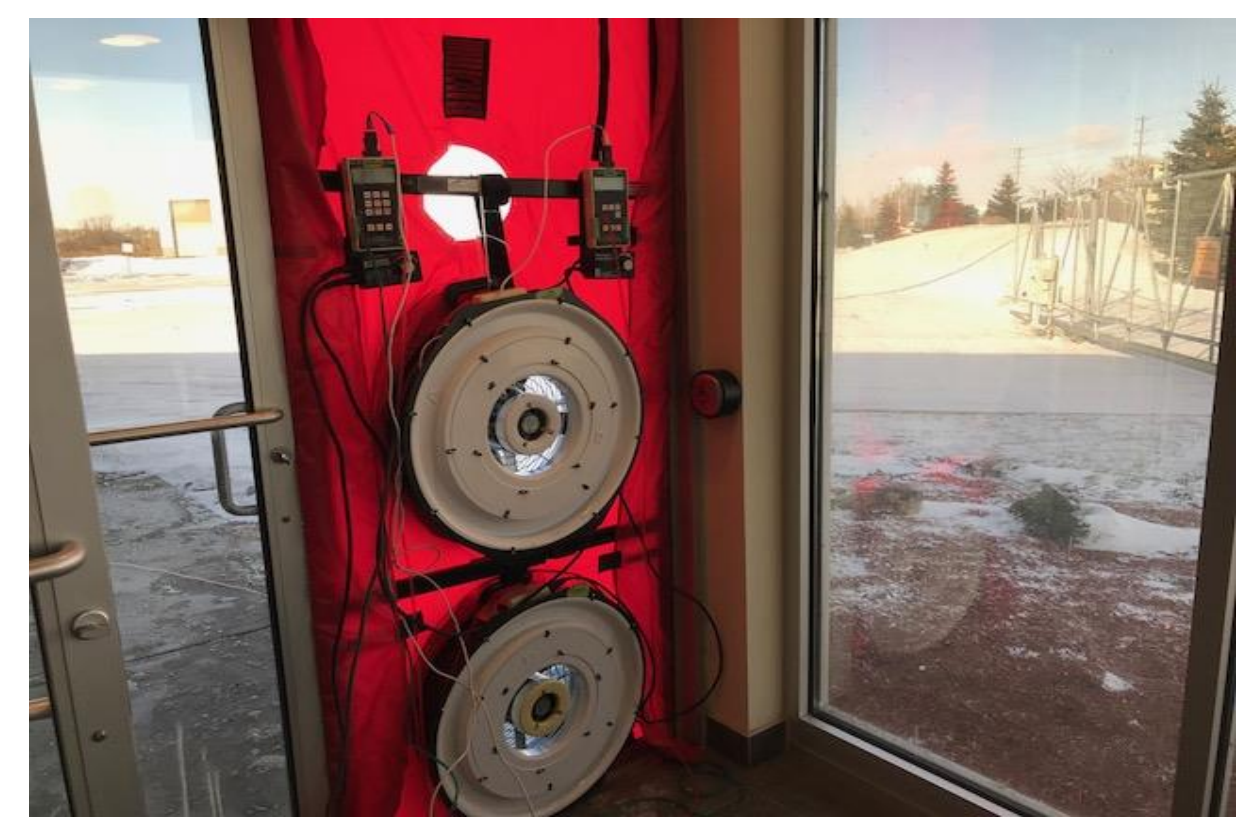

Figure 8: Air-leakage test (blower door test)

Table 9 provides the summary of the main input data and important parameters used as input to the eQUEST for the modeling of both GEHP and RTU. The specific input data used for the simulation of RTU is represented in Table 10. Table 11 indicates the specific input data used for the eQUEST simulation of GEHP. 
Table 9: Input data used in the simulation of GEHP and RTU

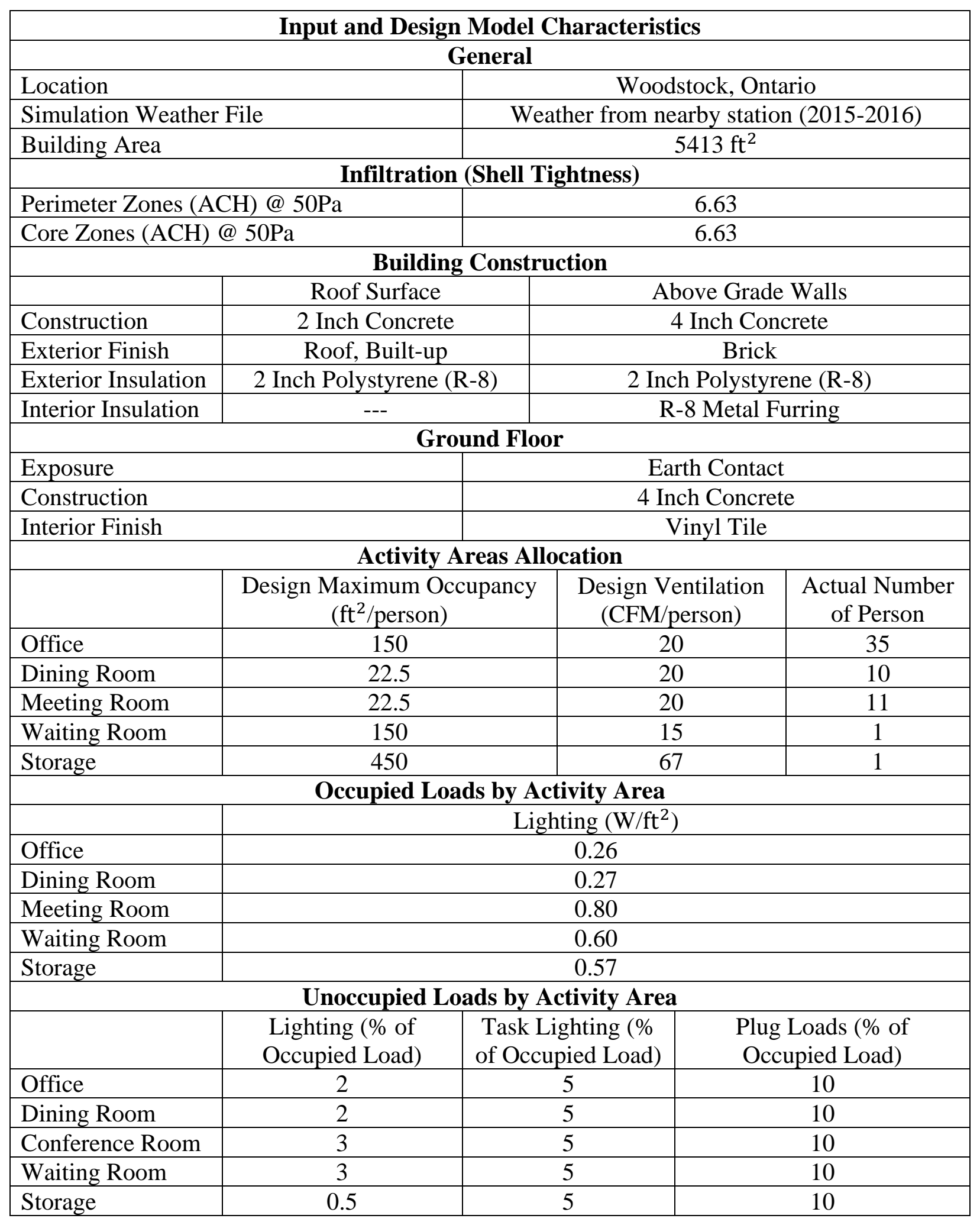


Table 10: Input data used for the simulation of the roof top unit (RTU)

\begin{tabular}{|c|c|c|}
\hline \multicolumn{3}{|c|}{ Thermostat } \\
\hline & Occupied & Unoccupied \\
\hline Cooling Set Point $\left({ }^{\circ} \mathrm{F}\right)$ & 76 & 82 \\
\hline Heating Set Point $\left({ }^{\circ} \mathrm{F}\right)$ & 75 & 70 \\
\hline \multicolumn{3}{|c|}{ Design Temperature and Air Flows } \\
\hline & Indoor & Supply \\
\hline Cooling Design Temperature $\left({ }^{\circ} \mathrm{F}\right)$ & 75 & 55 \\
\hline Heating Design Temperature $\left({ }^{\circ} \mathrm{F}\right)$ & 72 & 90 \\
\hline Minimum Design Flow $\left(\mathrm{CFM} / \mathrm{ft}^{2}\right)$ & \multicolumn{2}{|c|}{0.5} \\
\hline \multicolumn{3}{|c|}{ HVAC System Definition } \\
\hline Cooling Source & \multicolumn{2}{|c|}{ DX Coils } \\
\hline Heating Source & \multicolumn{2}{|c|}{ Furnace } \\
\hline System Type & \multicolumn{2}{|c|}{ Packaged multiple Zone DX with Furnace } \\
\hline Return Air Path & \multicolumn{2}{|c|}{ Ducted } \\
\hline \multicolumn{3}{|c|}{ Package HVAC Equipment } \\
\hline \multicolumn{3}{|c|}{ Cooling } \\
\hline Overall Size (Tons) & \multicolumn{2}{|c|}{17.5} \\
\hline Condenser Type & \multicolumn{2}{|c|}{ Air-Cooled } \\
\hline Efficiency (EER) & \multicolumn{2}{|c|}{10.1} \\
\hline \multicolumn{3}{|c|}{ Heating } \\
\hline Size $(\mathrm{kBtu} / \mathrm{h})$ & \multicolumn{2}{|c|}{323} \\
\hline Efficiency & \multicolumn{2}{|c|}{0.6} \\
\hline \multicolumn{3}{|c|}{ Economizer } \\
\hline Type & \multicolumn{2}{|c|}{ Dry bulb Temperature } \\
\hline High Limit $\left({ }^{\circ} \mathrm{F}\right)$ & \multicolumn{2}{|c|}{65} \\
\hline Low Limit $\left({ }^{\circ} \mathrm{F}\right)$ & \multicolumn{2}{|c|}{-2} \\
\hline \multicolumn{3}{|c|}{ Ventilation } \\
\hline Ventilation Fans (BHP) & \multicolumn{2}{|c|}{1.2} \\
\hline
\end{tabular}

The monthly plug loads used in eQUEST simulation for both GEHP and RTU models are shown in Table 12. The monthly plug loads are altered to the points that both GEHP and RTU models' results come in the range of acceptance of calibration criteria from ASHRAE which is described in the following. It is shown that the maximum plug loads are in May and June and the minimum is in April. 
Table 11: Input data used for the simulation of the GEHP system

\begin{tabular}{|c|c|c|}
\hline \multicolumn{3}{|c|}{ HVAC System } \\
\hline Cooling Source & & Coils \\
\hline Heating Source & \multicolumn{2}{|c|}{ DX Coils (Heat Pump) } \\
\hline Heat Pump Source & \multirow{2}{*}{\multicolumn{2}{|c|}{$\begin{array}{c}\text { Air } \\
\text { Packaged Terminal Heat Pump }\end{array}$}} \\
\hline System Type & & \\
\hline Supply Fan & \multicolumn{2}{|c|}{$0.619 \mathrm{~kW}(0.83 \mathrm{BHP})$} \\
\hline Overall Cooling size & \multicolumn{2}{|c|}{$56 \mathrm{~kW}(15.9$ Tons $)$} \\
\hline Overall heating size & \multicolumn{2}{|c|}{$63 \mathrm{~kW}(215 \mathrm{kBtu} / \mathrm{h})$} \\
\hline Cooling COP (EER) & \multicolumn{2}{|c|}{$1.3(4.4)$} \\
\hline Heating COP & \multicolumn{2}{|c|}{1.4} \\
\hline \multicolumn{3}{|c|}{ Thermostats } \\
\hline & Occupied & Unoccupied \\
\hline Cooling Set points $\left({ }^{\circ} \mathrm{F}\right)$ & 76 & 82 \\
\hline Heating Set Points $\left({ }^{\circ} \mathrm{F}\right)$ & 75 & 70 \\
\hline Thermostat Location & \multicolumn{2}{|c|}{ Within Zone } \\
\hline \multicolumn{3}{|c|}{ Design Temperature and Air Flows } \\
\hline & Indoor & Supply \\
\hline Cooling Design Temperature $\left({ }^{\circ} \mathrm{F}\right)$ & 75 & 55 \\
\hline Heating Design Temperature $\left({ }^{\circ} \mathrm{F}\right)$ & 75 & 100 \\
\hline Minimum Design Flow $\left(\mathrm{CFM} / \mathrm{ft}^{2}\right)$ & \multicolumn{2}{|c|}{0.5} \\
\hline
\end{tabular}

Table 12: Monthly plug loads

\begin{tabular}{|c|c|}
\hline Month & Plug loads $\left(\mathbf{W} / \mathbf{f t}^{\mathbf{2}}\right)$ \\
\hline 1 & 110.81 \\
\hline 2 & 110.81 \\
\hline 3 & 110.81 \\
\hline 4 & 20.579 \\
\hline 5 & 712.35 \\
\hline 6 & 712.35 \\
\hline 7 & 459.07 \\
\hline 8 & 474.9 \\
\hline 9 & 554.05 \\
\hline 10 & 47.49 \\
\hline 11 & 110.81 \\
\hline 12 & 110.81 \\
\hline
\end{tabular}


In Table 9 the unoccupied loads for lighting and task lighting are the percentage of the occupied loads from the same table. However, the unoccupied loads for plug loads are the percentage of loads in Table 12.

\section{Simulation Validation}

The simulated energy consumption was compared with the regression analysis obtained from the actual energy consumption. The data which were provided to the team was not complete for a full year and for some months, the data were not fully complete for the whole month. Moreover, the data were for every other month which means RTU gas and electricity consumption were gathered for a month, then the building had been switched over to the GEHP for the next month. Therefore, regression analysis was done based on actual data. However, only matching between the simulation result and regression is not enough. The accuracy of the comparison needs to be determined. For this, the ASHRAE Guideline 14-2002 [34], a building simulation criterion, has been adopted in order to verify the accuracy the eQUEST simulation. Two statistical indices, the Normalized Mean Bias Error (NMBE) and Coefficient of Variation of the Root Mean Square Error (CVRMSE) were determined. The NMBE and CVRMSE were calculated by using Equations (1) and (2):

$$
\begin{aligned}
& \text { NMBE }=\frac{1}{\bar{y}} \frac{\sum_{i=1}^{n}\left(y_{i}-\hat{y}_{i}\right)}{n} \times 100 \\
& \text { CVRMSE }=\frac{1}{\bar{y}}\left[\frac{\left.\sum_{i=1}^{n}\left(y_{i}-\hat{y}_{i}\right)\right)^{2}}{n}\right]^{1 / 2} \times 100
\end{aligned}
$$

where

$y_{i}$ is measured or actual energy consumption

$\hat{y}_{i} \quad$ simulated energy consumption

$\bar{y} \quad$ mean of the actual energy consumption

$n \quad$ the number of data used in the calibration.

These ASHRAE criteria can be applied for the data on monthly or hourly basis. For monthly data, the range of acceptance is such that the absolute value of NMBE is less than 5\% and that of CVRMSE is less than 15\% [34] as indicated in Table 13. 
Table 13: Range of acceptance of calibration criteria from ASHRAE Guideline 14-2002, for NMBE and CVRMSE [34]

\begin{tabular}{|l|c|c|}
\hline & NMBE (\%) & CVRMSE (\%) \\
\hline Monthly & \pm 5 & \pm 15 \\
\hline Hourly & \pm 10 & \pm 30 \\
\hline
\end{tabular}

RTU and GEHP calibration results are shown in Table 14. It has been calculated that NMBE and CVRMSE for the GEHP gas consumption was $4.02 \%$ and $13.93 \%$ respectively. For the GEHP electricity consumption, the calculated NMBE was 3.91\% while CVRMSE was $13.53 \%$. For the Rooftop Unit (RTU), the calculated NMBE and CVRMSE value for the gas consumption were $1.38 \%$ and $4.79 \%$ respectively. For the electricity consumption, the value obtained for NMBE was $-3.43 \%$, while that of CVRMSE was $11.89 \%$. It can be easily seen that the NMBE and CVRMSE for both the gas and electricity consumption of GEHP and RTU are within the range of the ASHRAE calibration criteria with the calibrated monthly plug loads in Table 14. It should be mentioned that the regression analysis was performed based on the measured data from the same year that both RTU and GEHP models were developed.

Since both GEHP and RTU simulation results are in the range of acceptance of calibration criteria from ASHRAE Guideline 14-2002, these models are developed for other major cities in Ontario to compare how GEHP and RTU perform in different regions.

Table 14: GEHP and RTU calibration results obtained from ASHRAE Guideline 14-2002

\begin{tabular}{|l|c|c|}
\hline & NMBE (\%) & CVRMSE (\%) \\
\hline Monthly GEHP Gas Consumption & 4.02 & 13.93 \\
\hline Monthly GEHP Electricity Consumption & 3.91 & 13.53 \\
\hline Monthly RTU Gas Consumption & -1.38 & 4.79 \\
\hline Monthly RTU Electricity Consumption & -3.43 & 11.89 \\
\hline
\end{tabular}

\section{Simulation Results and Discussion}

In this section, results obtained by running eQUEST simulation software for both GEHP and RTU are discussed. Comparison of the simulation results and regression analysis are presented in graphs. The regression analysis obtained from measured data is presented in Table 15. 
Table 15: Monthly gas and electricity consumption of GEHP and RTU obtained from regression analysis for Woodstock

\begin{tabular}{|c|c|c|c|c|c|c|}
\hline \multicolumn{7}{|c|}{ Regression Analysis Data } \\
\hline \multirow[b]{2}{*}{ Months } & \multicolumn{3}{|c|}{ GEHP } & \multicolumn{3}{|c|}{ RTU } \\
\hline & $\begin{array}{c}\text { Gas } \\
\text { Consumption } \\
\left(\mathbf{m}^{3}\right)\end{array}$ & $\begin{array}{c}\text { Electricity } \\
\text { Consumption } \\
(\mathrm{kWh})\end{array}$ & $\begin{array}{c}\text { Total Energy } \\
\text { Consumption } \\
(\mathrm{MJ})\end{array}$ & $\begin{array}{c}\text { Gas } \\
\text { Consumption } \\
\left(\mathbf{m}^{3}\right)\end{array}$ & $\begin{array}{c}\text { Electricity } \\
\text { Consumption } \\
(\mathrm{kWh})\end{array}$ & $\begin{array}{c}\text { Total Energy } \\
\text { Consumption } \\
(\mathrm{MJ})\end{array}$ \\
\hline January & 1,520 & 1,773 & 64,148 & 1,795 & 1,153 & 72,367 \\
\hline February & 1,274 & 1,659 & 54,389 & 1,540 & 1,079 & 62,410 \\
\hline March & 1,009 & 1,716 & 44,523 & 1,302 & 1,116 & 53,498 \\
\hline April & 817 & 1,544 & 36,607 & 1,087 & 1,004 & 44,924 \\
\hline May & 417 & 1,178 & 20,088 & - & 2,151 & 7,743 \\
\hline June & 299 & 878 & 14,524 & - & 2,486 & 8,949 \\
\hline July & 415 & 878 & 18,932 & - & 3,501 & 12,603 \\
\hline August & 445 & 1,089 & 20,832 & - & 3,728 & 13,420 \\
\hline September & 370 & 913 & 17,348 & - & 3,095 & 11,142 \\
\hline October & 428 & 1,144 & 20,384 & 638 & 744 & 26,924 \\
\hline November & 688 & 1,430 & 31,294 & 941 & 930 & 39,109 \\
\hline December & 961 & 1,773 & 42,904 & 1,269 & 1,153 & 52,377 \\
\hline Total & 8,643 & 15,975 & 385,978 & 8,572 & 22,140 & 405,474 \\
\hline
\end{tabular}

The simulation result indicated in Table 16 showed that the peak heating and cooling loads are $79.82 \mathrm{~kW}$ and $62.97 \mathrm{~kW}$, respectively.

Table 16: Peak heating and cooling loads obtained from eQUEST simulation

\begin{tabular}{|c|c|}
\hline & $\mathrm{kW}$ \\
\hline Peak Heating & 79.82 \\
\hline Peak Cooling & 62.97 \\
\hline
\end{tabular}

Figure 9 shows the monthly variation of the gas consumption of the roof top units (RTUs) (obtained from the eQUEST simulation) and regression analysis. It can be seen that the gas consumption increases after summer months towards fall and winter months. In order to provide the heating supply, the RTU has the furnace that runs on natural gas. Since from May to September is the cooling season (no space heating is needed), the RTU is only utilized to provide cooling load, hence the RTU furnace was off during this period. As a result, there was no gas consumed by the RTU during the cooling season. Due to this reason, for both regression analysis and eQUEST model, the consumption of the gas is nil for the summer months. 
From Figure 9, it can also be noticed that the maximum difference between the model and regression analysis is $23.53 \%$ and this was seen in October. However, for the other months the difference was less than $10 \%$. The difference of the total annual gas consumption between the regression analysis and the model was $1.38 \%$.

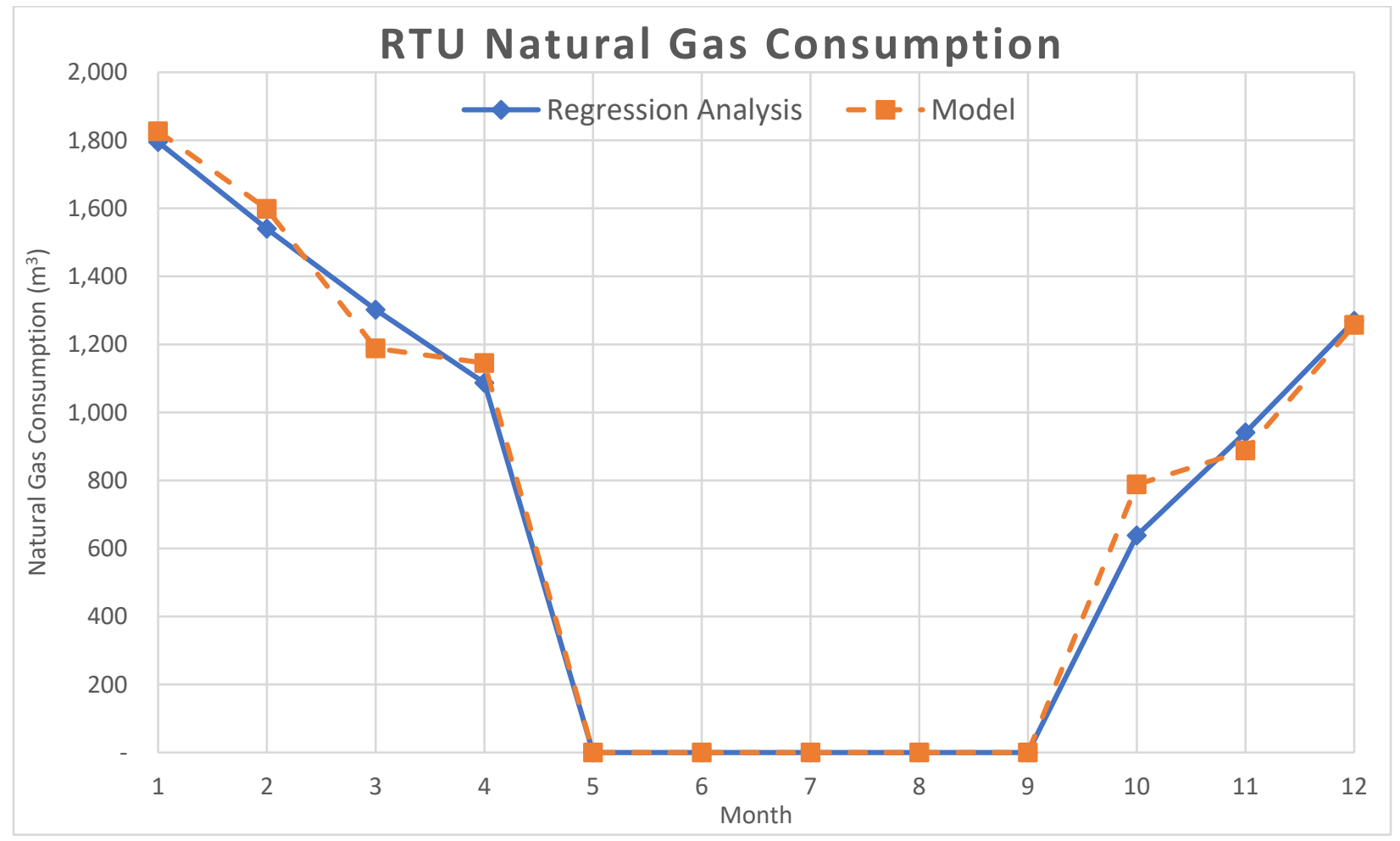

Figure 9: Comparison of simulation and regression analysis of monthly variation of RTU gas consumption for Woodstock

The roof top unit monthly electricity consumption was indicated by Figure 10. It can be seen from Figure 10 that the overall trend of the electrical consumption estimated by the eQUEST simulation matches with regression analysis. The total annual difference between eQUEST and regression analysis is only $3.43 \%$. 


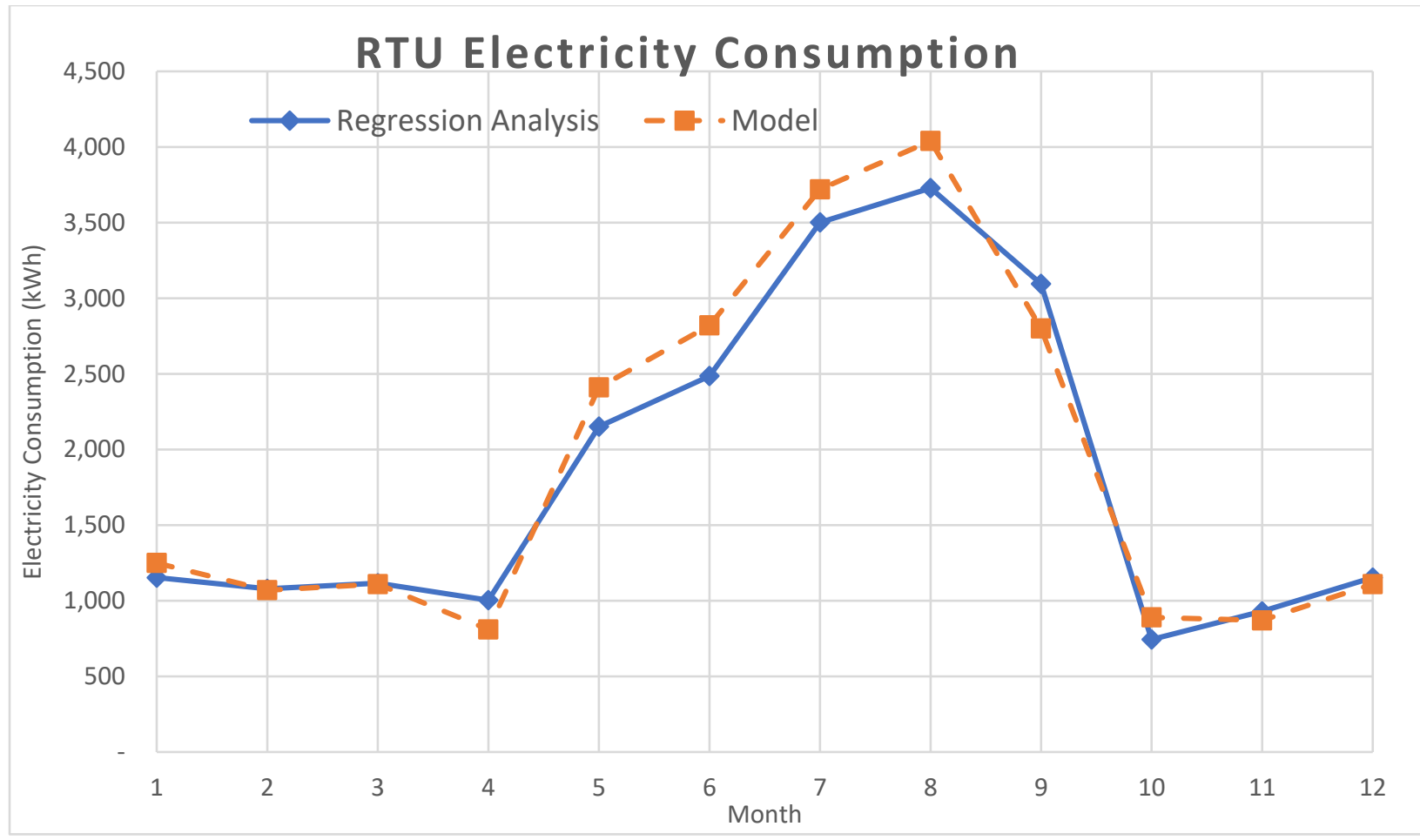

Figure 10: Comparison of simulation and regression analysis of monthly variation of RTU electricity consumption for Woodstock.

Figure 11 describes the variation of monthly gas consumption utilized by GEHP. This Figure also compares the results of the modeling and regression analysis. The simulation result obtained from eQUEST modeling is very close to the regression analysis. The percentage difference of the annual consumption between the two analyses is around $4.02 \%$.

Figure 12 presents the monthly electrical energy consumed by the GEHP. It can be seen that the overall electrical consumption trend of the model is similar to that of regression analysis. The percentage of difference of the total electrical energy consumption between the two analyses is $3.91 \%$.

The monthly gas and electricity consumption for both GEHP and RTU are shown in Table 17 for Woodstock building. It could be seen that gas, electricity and total energy consumption of GEHP are less than RTU consumption. 


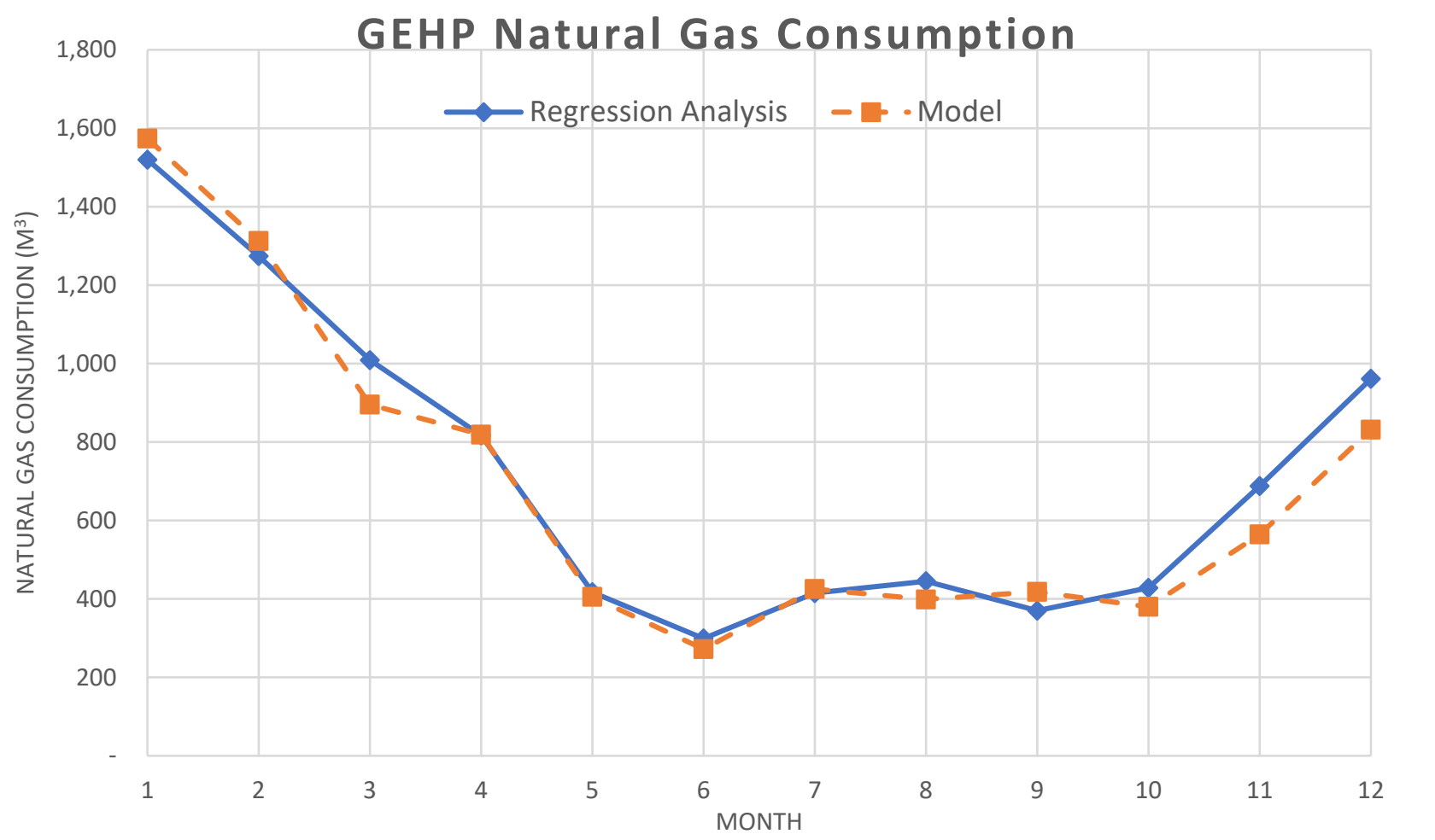

Figure 11: Comparison of simulation and regression analysis of monthly variation of GEHP natural gas consumption for Woodstock

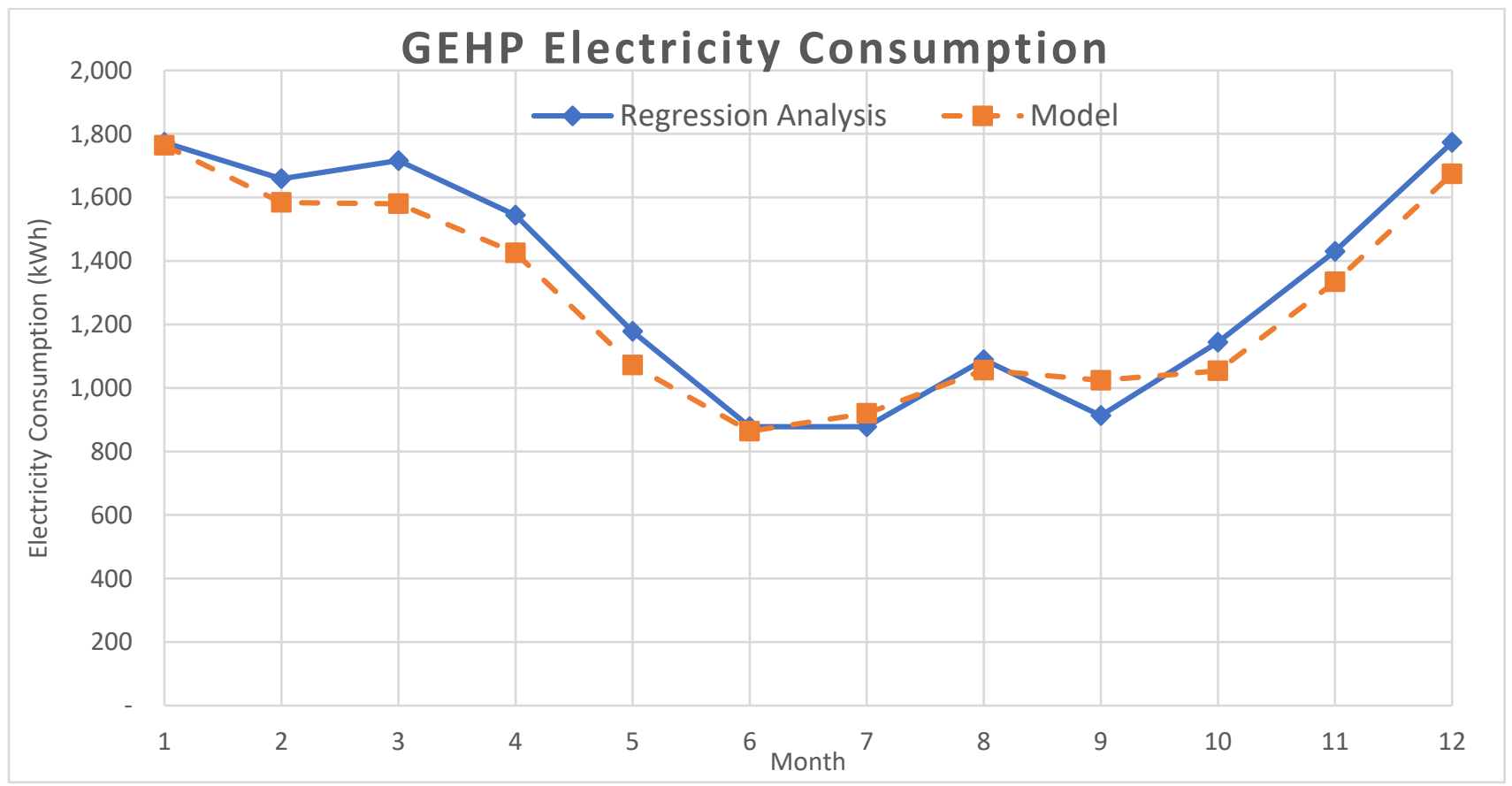

Figure 12: Comparison of simulation and regression analysis of monthly variation of GEHP electricity consumption for Woodstock 
Table 17: Simulated monthly gas and electricity consumption of GEHP and RTU for Woodstock

\begin{tabular}{|c|c|c|c|c|c|c|}
\hline \multicolumn{7}{|c|}{ MQUEST Simulation Results for Woodstock } \\
\cline { 2 - 7 } Months & $\begin{array}{c}\text { GEHP } \\
\text { Consumption } \\
\left(\mathrm{m}^{3}\right)\end{array}$ & $\begin{array}{c}\text { Electricity } \\
\text { Consumption } \\
(\mathrm{kWh})\end{array}$ & $\begin{array}{c}\text { Total Energy } \\
\text { Consumption } \\
(\mathrm{MJ})\end{array}$ & $\begin{array}{c}\text { Gas } \\
\text { Consumption } \\
\left(\mathrm{m}^{3}\right)\end{array}$ & $\begin{array}{c}\text { Electricity } \\
\text { Consumption } \\
(\mathrm{kWh})\end{array}$ & $\begin{array}{c}\text { Total Energy } \\
\text { Consumption } \\
(\mathrm{MJ})\end{array}$ \\
\hline January & 1,574 & 1,764 & 64,956 & 1,826 & 1,250 & 73,908 \\
\hline February & 1,312 & 1,584 & 54,581 & 1,598 & 1,070 & 64,594 \\
\hline March & 895 & 1,580 & 39,037 & 1,188 & 1,110 & 49,149 \\
\hline April & 819 & 1,425 & 35,630 & 1,145 & 810 & 46,432 \\
\hline May & 405 & 1,072 & 18,946 & - & 2,410 & 8,676 \\
\hline June & 272 & 864 & 13,238 & - & 2,820 & 10,152 \\
\hline July & 425 & 920 & 19,148 & - & 3,720 & 13,392 \\
\hline August & 399 & 1,056 & 18,645 & - & 4,040 & 14,544 \\
\hline September & 418 & 1,024 & 19,258 & - & 2,800 & 10,080 \\
\hline October & 380 & 1,054 & 17,942 & 788 & 890 & 33,155 \\
\hline November & 564 & 1,334 & 25,818 & 888 & 870 & 36,873 \\
\hline December & 832 & 1,674 & 37,001 & 1,257 & 1,110 & 51,765 \\
\hline Total & 8,295 & 15,351 & 364,199 & 8,691 & 22,900 & 412,720 \\
\hline
\end{tabular}

Both GEHP and RTU models' results are in range of acceptance of calibration criteria from ASHRAE Guideline 14-2002 in terms of gas and electricity consumptions. Therefore, the developed models are applied for four major cities in Ontario; Windsor, Toronto, Ottawa and Thunder Bay to investigate the performance of GEHP and RTU in those regions. By comparing the outcomes, it could be concluded that in which regions replacing RTU with GEHP have higher benefits in terms of energy saving, GHG saving and cost.

By performing eQUEST simulation for heating and cooling seasons, total space heating and cooling demands are found 299.36 MBTU and 81.28 MBTU, respectively. Therefore, with respect to the amount of energy consumed in heating and cooling seasons for GEHP, seasonal heating and cooling COPs for GEHP are 1.33 and 1.2, respectively, which are below the actual values used in the simulation.

eQUEST enjoys a decent library of weather data. Hence, the same exact models are simulated for Windsor, Toronto, Ottawa and Thunder Bay with relevant weather data.

Windsor is a city in Ontario, across the Detroit River from the U.S. Monthly gas and electricity consumptions of GEHP and RTU for Windsor from eQUEST simulation are represented in Table 18. The highest gas and electricity consumptions of GEHP are shown in January which are $1,435 \mathrm{~m}^{3}$ and $1,836 \mathrm{kWh}$, respectively. Whereas the month of June has the rock-bottom 
consumptions, which are $286 \mathrm{~m}^{3}$ and $896 \mathrm{kWh}$ for gas and electricity, respectively. In the Cooling season, from May to September, gas consumption is zero for RTU. In the month of January, RTU gas consumption touches the highest point, $1,629 \mathrm{~m}^{3}$. RTU electricity consumption culminates in August at 4,370 kWh. The annual total energy consumption of GEHP and RTU are 358,524 MJ and 379,669 MJ, respectively, indicating the fact that 21,145 MJ can be annually saved by using GEP instead of RTU in Windsor.

Table 18: Simulated monthly gas and electricity consumption of GEHP and RTU for Windsor

\begin{tabular}{|c|c|c|c|c|c|c|}
\hline \multicolumn{7}{|c|}{ MQUEST Simulation Results for Windsor } \\
\cline { 2 - 7 } & $\begin{array}{c}\text { GEHP } \\
\text { Consumption } \\
\left(\mathrm{m}^{3}\right)\end{array}$ & $\begin{array}{c}\text { Electricity } \\
\text { Consumption } \\
(\mathrm{kWh})\end{array}$ & $\begin{array}{c}\text { Total Energy } \\
\text { Consumption } \\
(\mathrm{MJ})\end{array}$ & $\begin{array}{c}\text { Gas } \\
\text { Consumption } \\
\left(\mathrm{m}^{3}\right)\end{array}$ & $\begin{array}{c}\text { Electricity } \\
\text { Consumption } \\
(\mathrm{kWh})\end{array}$ & $\begin{array}{c}\text { Total Energy } \\
\text { Consumption } \\
(\mathrm{MJ})\end{array}$ \\
\hline January & 1,453 & 1,836 & 60,731 & 1,629 & 1,230 & 66,354 \\
\hline February & 1,211 & 1,656 & 51,073 & 1,375 & 1,080 & 56,125 \\
\hline March & 719 & 1,584 & 32,478 & 1,075 & 1,130 & 44,936 \\
\hline April & 500 & 1,368 & 23,556 & 998 & 780 & 40,726 \\
\hline May & 431 & 1,120 & 20,089 & - & 2,730 & 9,828 \\
\hline June & 286 & 896 & 13,881 & - & 3,810 & 13,716 \\
\hline July & 387 & 992 & 17,972 & - & 4,100 & 14,760 \\
\hline August & 397 & 1,000 & 18,381 & - & 4,370 & 15,732 \\
\hline September & 427 & 992 & 19,460 & - & 3,330 & 11,988 \\
\hline October & 526 & 1,152 & 23,749 & 696 & 790 & 29,285 \\
\hline November & 635 & 1,188 & 27,930 & 754 & 820 & 31,600 \\
\hline December & 1,153 & 1,746 & 49,224 & 1,076 & 1,030 & 44,619 \\
\hline Total & 8,126 & 15,530 & 358,524 & 7,603 & 25,200 & 379,669 \\
\hline
\end{tabular}

Toronto, the capital of the province of Ontario, is a major Canadian city along Lake Ontario's northwestern shore. Monthly gas and electricity consumptions of GEHP and RTU for Toronto from eQUEST simulation are illustrated in Table 19. Gas and electricity consumption of GEHP climaxes in January which are $1,370 \mathrm{~m}^{3}$ and $1,692 \mathrm{kWh}$, respectively. The lowest gas and electricity consumption of GEHP are $298 \mathrm{~m}^{3}$ and $896 \mathrm{kWh}$, respectively, in June. Gas consumption is zero for RTU from May to September. Gas and electricity consumption for RTU peaks in January $\left(1,732 \mathrm{~m}^{3}\right)$ and August $(4,160 \mathrm{kWh})$, respectively. Total annual energy consumption of GEHP and RTU are 351,791 MJ and 405,763 MJ, respectively. Consequently, there is an annual potential of 53,972 MJ energy saving by applying GEHP in Toronto. 
Table 19: Simulated monthly gas and electricity consumption of GEHP and RTU for Toronto

\begin{tabular}{|c|c|c|c|c|c|c|}
\hline \multicolumn{7}{|c|}{ eQUEST Simulation Results for Toronto } \\
\hline \multirow[b]{2}{*}{ Months } & \multicolumn{3}{|c|}{ GEHP } & \multicolumn{3}{|c|}{ RTU } \\
\hline & $\begin{array}{c}\text { Gas } \\
\text { Consumption } \\
\left(\mathrm{m}^{3}\right)\end{array}$ & $\begin{array}{c}\text { Electricity } \\
\text { Consumption } \\
\text { (kWh) }\end{array}$ & $\begin{array}{c}\text { Total Energy } \\
\text { Consumption } \\
\text { (MJ) }\end{array}$ & $\begin{array}{c}\text { Gas } \\
\text { Consumption } \\
\left(\mathrm{m}^{3}\right)\end{array}$ & $\begin{array}{l}\text { Electricity } \\
\text { Consumption } \\
\text { (kWh) }\end{array}$ & $\begin{array}{l}\text { Total Energy } \\
\text { Consumption } \\
\text { (MJ) }\end{array}$ \\
\hline January & 1,370 & 1,692 & 57,122 & 1,732 & 1,140 & 69,938 \\
\hline February & 1,247 & 1,540 & 51,985 & 1,528 & 1,070 & 61,935 \\
\hline March & 876 & 1,512 & 38,064 & 1,251 & 1,130 & 51,611 \\
\hline April & 605 & 1,440 & 27,729 & 1,182 & 980 & 48,465 \\
\hline May & 444 & 1,120 & 20,574 & - & 2,580 & 9,288 \\
\hline June & 298 & 896 & 14,335 & - & 3,350 & 12,060 \\
\hline July & 466 & 1,088 & 21,261 & - & 4,020 & 14,472 \\
\hline August & 403 & 1,024 & 18,689 & - & 4,160 & 14,976 \\
\hline September & 409 & 960 & 18,690 & - & 2,400 & 8,640 \\
\hline October & 609 & 1,152 & 26,819 & 732 & 920 & 31,131 \\
\hline November & 557 & 1,170 & 24,964 & 924 & 870 & 38,229 \\
\hline December & 696 & 1,566 & 31,559 & 1,078 & 1,120 & 45,018 \\
\hline Total & 7,981 & 15,160 & 351,791 & 8,428 & 23,740 & 405,763 \\
\hline
\end{tabular}

Ottawa is Canada's capital, in the east of southern Ontario. Monthly gas and electricity consumption of GEHP and RTU from eQUEST simulation for Ottawa are shown in Table 20. Both gas and electricity of GEHP climaxes in January at $1,346 \mathrm{~m}^{3}$ and 1,710 $\mathrm{kWh}$, respectively. GEHP uses the minimum amount of gas and electricity in June at $291 \mathrm{~m}^{3}$ and $896 \mathrm{kWh}$, respectively. While RTU does not consume gas in cooling season from May to September, it touches the highest consumption in January at $1,735 \mathrm{~m}^{3}$. Highest and lowest electricity consumption of RTU are 4,170 kWh and $870 \mathrm{kWh}$ in August and November, respectively. Total annual energy consumption of GEHP and RTU for Ottawa are 359,095 MJ and 418,864 MJ, respectively. It could be seen that GEHP consumes 59,769 MJ less energy in a year compared with RTU.

Thunder Bay is a city on Lake Superior, in northwestern Ontario. Monthly gas and electricity consumption of GEHP and RTU for Thunder Bay from eQUEST simulation are demonstrated in Table 21. Same as other cities, the highest gas and electricity consumption of GEHP are in January at $1,759 \mathrm{~m}^{3}$ and $1,944 \mathrm{kWh}$, respectively. June has the minimum gas and electricity consumption of GEHP at $327 \mathrm{~m}^{3}$ and $928 \mathrm{kWh}$, respectively. The maximum gas and electricity consumption of RTU are in January and August at $1,812 \mathrm{~m}^{3}$ and $3,960 \mathrm{kWh}$, respectively. RTU does not consume gas in cooling season from May to September and the lowest electricity consumption is in October 
at $960 \mathrm{kWh}$. Total energy consumption is also compared for two models which are 408,471 MJ and 470,872 MJ for GEHP and RTU, respectively. Consequently, GEHP consumes 62,401 MJ less energy in a year compared with RTU.

Table 20: Simulated monthly gas and electricity consumption of GEHP and RTU for Ottawa

\begin{tabular}{|c|c|c|c|c|c|c|}
\hline \multicolumn{7}{|c|}{ eQUEST Simulation Results for Ottawa } \\
\hline \multirow[b]{2}{*}{ Months } & \multicolumn{3}{|c|}{ GEHP } & \multicolumn{3}{|c|}{ RTU } \\
\hline & $\begin{array}{c}\text { Gas } \\
\text { Consumption } \\
\left(\mathrm{m}^{3}\right)\end{array}$ & $\begin{array}{c}\text { Electricity } \\
\text { Consumption } \\
(\mathrm{kWh})\end{array}$ & $\begin{array}{l}\text { Total Energy } \\
\text { Consumption } \\
(\mathrm{MJ})\end{array}$ & $\begin{array}{c}\text { Gas } \\
\text { Consumption } \\
\left(\mathrm{m}^{3}\right)\end{array}$ & $\begin{array}{l}\text { Electricity } \\
\text { Consumption } \\
(\mathrm{kWh})\end{array}$ & $\begin{array}{c}\text { Total Energy } \\
\text { Consumption } \\
\text { (MJ) }\end{array}$ \\
\hline January & 1,346 & 1,710 & 56,300 & 1,735 & 1,140 & 70,024 \\
\hline February & 1,225 & 1,548 & 51,191 & 1,531 & 1,070 & 62,053 \\
\hline March & 859 & 1,476 & 37,322 & 1,249 & 1,130 & 51,546 \\
\hline April & 581 & 1,440 & 26,822 & 1,171 & 980 & 48,035 \\
\hline May & 436 & 1,120 & 20,279 & - & 2,580 & 9,288 \\
\hline June & 291 & 896 & 14,050 & - & 3,200 & 11,520 \\
\hline July & 458 & 1,072 & 20,897 & - & 3,980 & 14,328 \\
\hline August & 392 & 1,024 & 18,288 & - & 4,170 & 15,012 \\
\hline September & 400 & 944 & 18,306 & - & 2,400 & 8,640 \\
\hline October & 599 & 1,152 & 26,439 & 731 & 920 & 31,110 \\
\hline November & 548 & 1,152 & 24,561 & 920 & 870 & 38,089 \\
\hline December & 1,049 & 1,548 & 44,639 & 1,452 & 1,120 & 59,219 \\
\hline Total & 8,184 & 15,082 & 359,095 & 8,790 & 23,560 & 418,864 \\
\hline
\end{tabular}

RTU natural gas consumptions for all five mentioned cities are shown in Figure 13. It could be observed that the trends of all graphs are almost the same. For all five cities, RTU gas consumptions for cooling season from May to September are zero. Despite Thunder Bay which has the highest monthly gas consumption except for January and February, Windsor has the lowest monthly gas consumption in a year. 
Table 21: Simulated monthly gas and electricity consumption of GEHP and RTU for Thunder Bay

\begin{tabular}{|c|c|c|c|c|c|c|}
\hline \multicolumn{7}{|c|}{ eQUEST Simulation Results for Thunder Bay } \\
\hline \multirow[b]{2}{*}{ Months } & \multicolumn{3}{|c|}{ GEHP } & \multicolumn{3}{|c|}{ RTU } \\
\hline & $\begin{array}{c}\text { Gas } \\
\text { Consumption } \\
\left(\mathrm{m}^{3}\right)\end{array}$ & $\begin{array}{l}\text { Electricity } \\
\text { Consumption } \\
\text { (kWh) }\end{array}$ & $\begin{array}{c}\text { Total Energy } \\
\text { Consumption } \\
(\mathrm{MJ})\end{array}$ & $\begin{array}{c}\text { Gas } \\
\text { Consumption } \\
\left(\mathrm{m}^{3}\right)\end{array}$ & $\begin{array}{l}\text { Electricity } \\
\text { Consumption } \\
(\mathrm{kWh})\end{array}$ & $\begin{array}{c}\text { Total Energy } \\
\text { Consumption } \\
\text { (MJ) }\end{array}$ \\
\hline January & 1,759 & 1,944 & 72,503 & 1,812 & 1,440 & 74,043 \\
\hline February & 1,134 & 1,638 & 48,128 & 1,521 & 1,250 & 62,303 \\
\hline March & 1,028 & 1,746 & 44,561 & 1,471 & 1,380 & 60,854 \\
\hline April & 907 & 1,638 & 39,678 & 1,375 & 1,210 & 56,593 \\
\hline May & 419 & 1,088 & 19,531 & - & 2,560 & 9,216 \\
\hline June & 327 & 928 & 15,537 & - & 2,920 & 10,512 \\
\hline July & 486 & 1,120 & 22,136 & - & 3,740 & 13,464 \\
\hline August & 422 & 1,008 & 19,338 & - & 3,960 & 14,256 \\
\hline September & 454 & 1,024 & 20,588 & - & 2,090 & 7,524 \\
\hline October & 376 & 1,332 & 18,806 & 1,035 & 960 & 42,795 \\
\hline November & 551 & 1,404 & 25,585 & 1,235 & 1,090 & 50,864 \\
\hline December & 1,490 & 1,836 & 62,082 & 1,667 & 1,420 & 68,448 \\
\hline Total & 9,353 & 16,706 & 408,471 & 10,115 & 24,020 & 470,872 \\
\hline
\end{tabular}

Figure 14 shows RTU electricity consumption for all five cities. While August has the highest electricity consumption for all five cities, April and October have the minimum electricity consumptions. In the cooling season, from May to September, a significant increase could be seen in the graph, while in heating season, they all remain almost steady. Windsor and Thunder Bay have the highest electricity consumption in cooling and heating seasons, respectively.

Figure 15 shows RTU total energy consumption monthly. In the cooling season from May to September, all cities touch the lowest energy consumptions. Moving to heating season, a sharp increase in total energy consumption could be seen due to fall in outdoor temperature. Although Thunder Bay has the highest energy consumption in heating season except for February, Windsor consumes the lowest energy in heating season. The highest energy consumption is obtained in January for all five cities. 


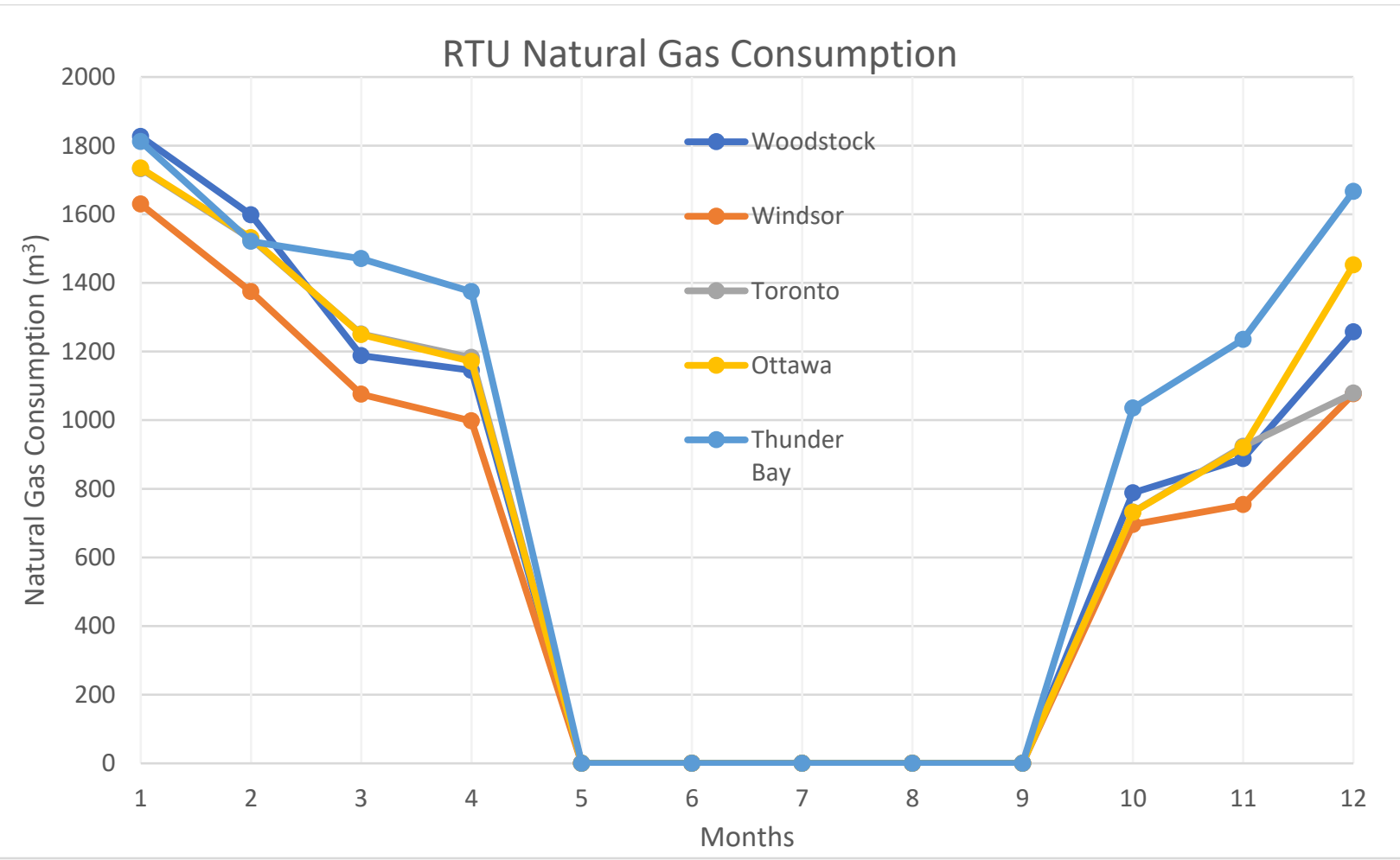

Figure 13: Comparison of RTU natural gas consumption

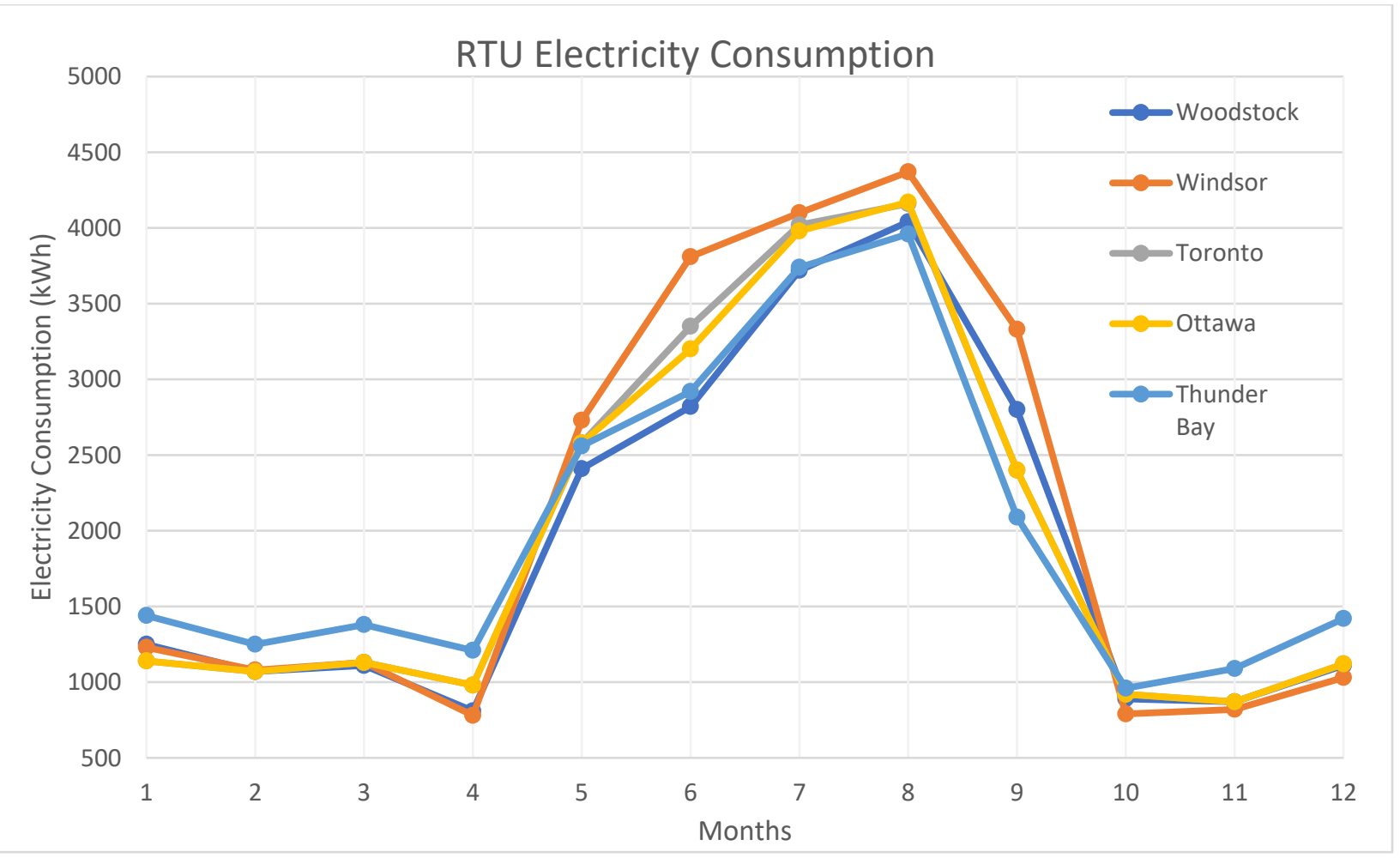

Figure 14: Comparison of RTU electricity consumption 


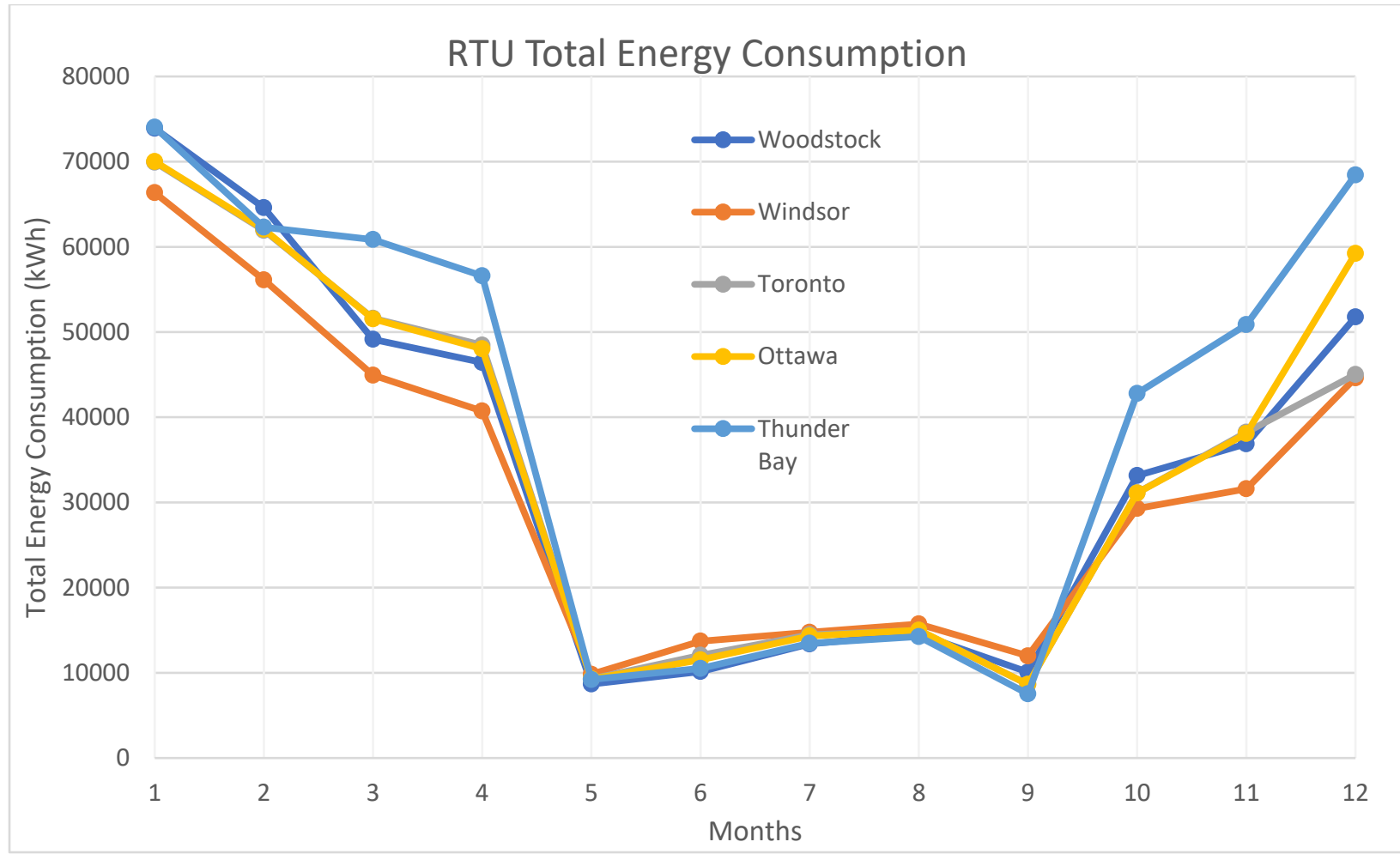

Figure 15: Comparison of RTU total energy consumption

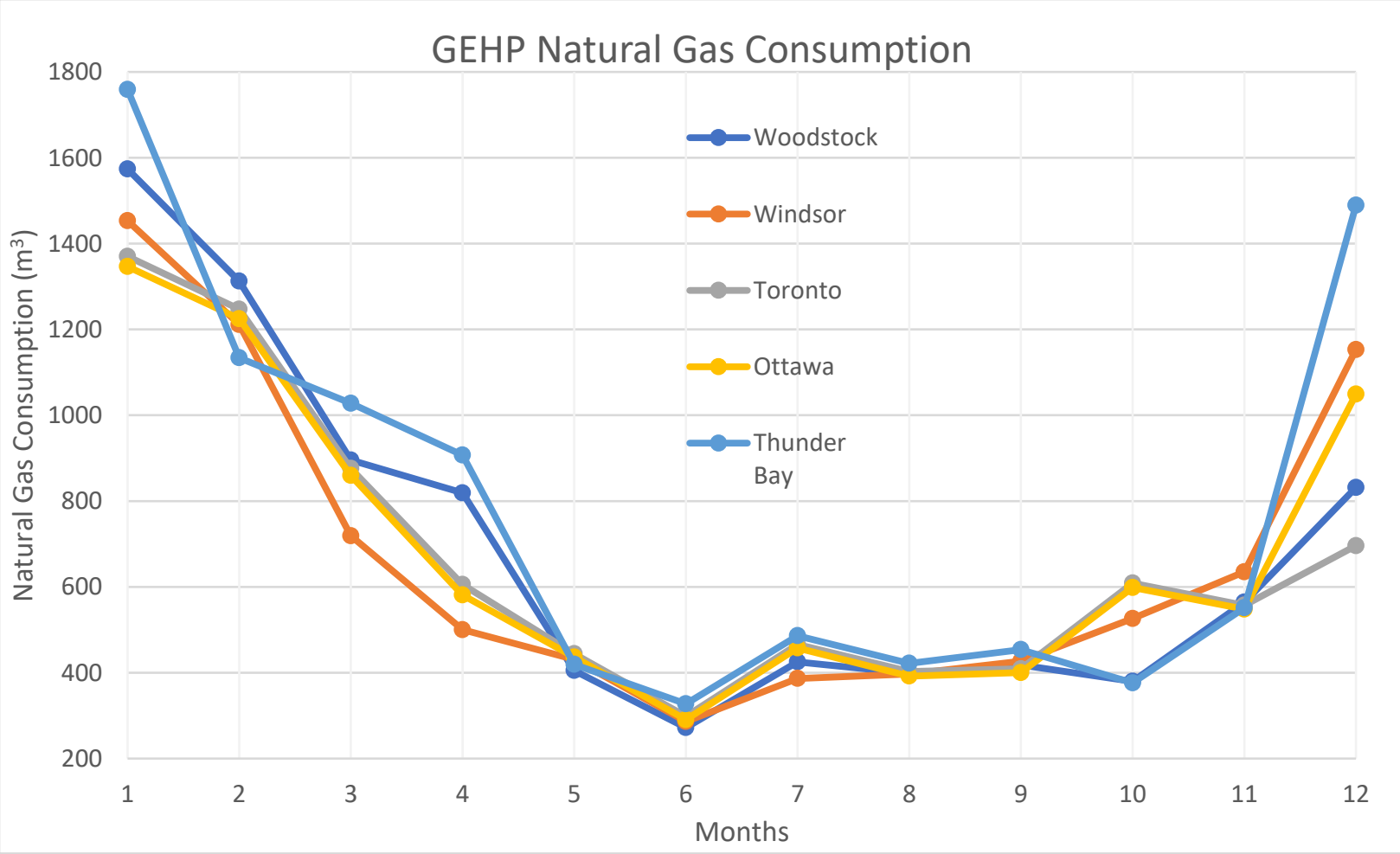

Figure 16: Comparison of GEHP natural gas consumption 
GEHP natural gas consumption for five mentioned cities are illustrated in Figure 16. All cities follow nearly the same pattern during the year. The minimum and maximum natural gas consumptions are in June and January for all cities, respectively. While there is not any remarkable difference in cooling season among all cities, Thunder Bay depicts relatively higher energy consumption compared with other cities in heating season.

Figure 17 represents GEHP electricity consumption in the five cities. The lowest and highest electricity consumptions are in June and January for all cities. In most on the months, Thunder bay electricity consumption is higher than the rest, however it follows the trend of the other cities approximately.

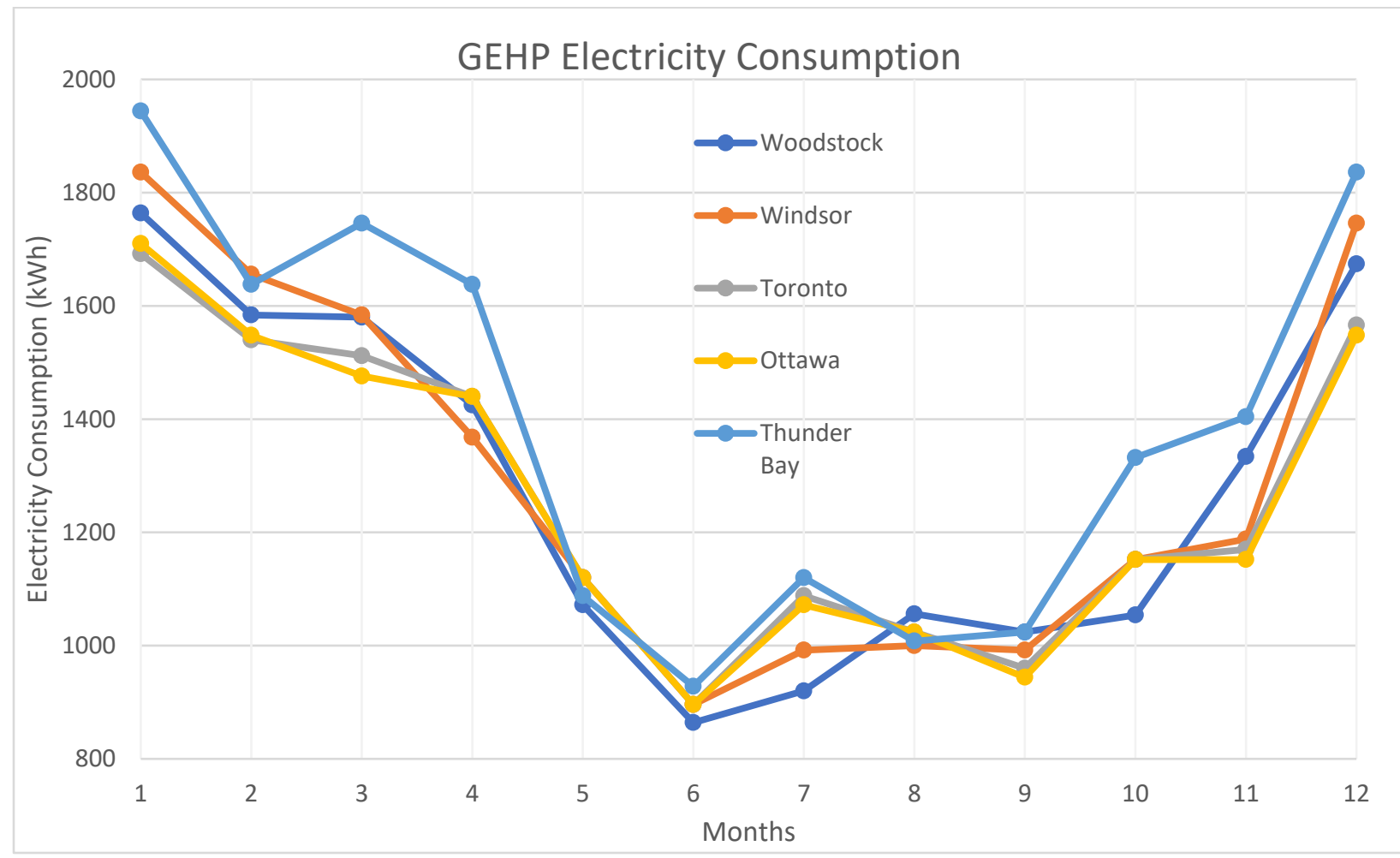

Figure 17: Comparison of GEHP electricity consumption

GEHP total energy consumption for all five cites are shown in Figure 18. June and January have the lowest and highest energy consumptions for all cities. It could be seen that the total energy consumption of GEHP drops in cooling season, while it gradually upsurges as we go towards heating season. 


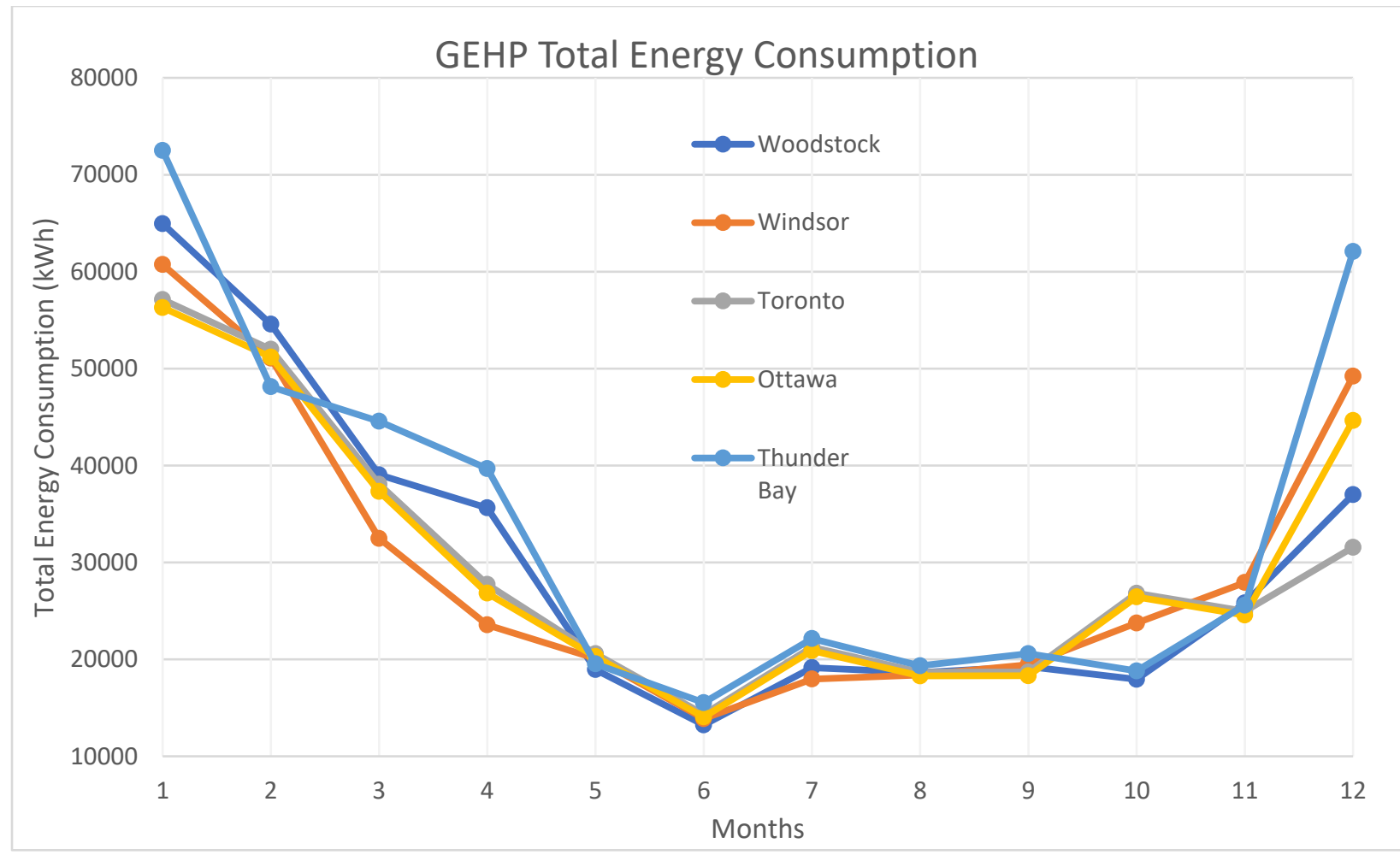

Figure 18: Comparison of GEHP total energy consumption

Figure 19 shows the annual natural gas consumption saving by applying GEHP instead of RTU in all five cities. The actual values are also represented in Table 22. Thunder Bay has the highest natural gas consumption saving $\left(761 \mathrm{~m}^{3}\right)$. Ottawa and Toronto come next and their natural gas consumption saving are $605 \mathrm{~m}^{3}$ and $447 \mathrm{~m}^{3}$, respectively. Woodstock has the lowest annual natural gas consumption saving at $395 \mathrm{~m}^{3}$, on the other hand, using GEHP instead of RTU consumes more natural gas in Windsor. Therefore, GEHP does not provide any natural gas consumption saving in Windsor and GEHP consumes $523 \mathrm{~m}^{3}$ more natural gas than RTU in a year.

Annual electricity consumption saving by using GEHP instead of RTU is shown in Figure 20 and the values are represented in Table 23. Despite natural gas consumption saving trend, Windsor has the highest possible electricity consumption saving at 9,670 kWh. Both Toronto and Ottawa come in second place, however, Toronto has slightly higher annual electricity consumption saving than Ottawa. The actual annual electricity consumption saving for Toronto and Ottawa are 8,580 $\mathrm{kWh}$ and 8,478 $\mathrm{kWh}$, respectively. The amount of annual energy saving for Woodstock and Thunder Bay are 7,549 kWh and 7,314 kWh, respectively. 


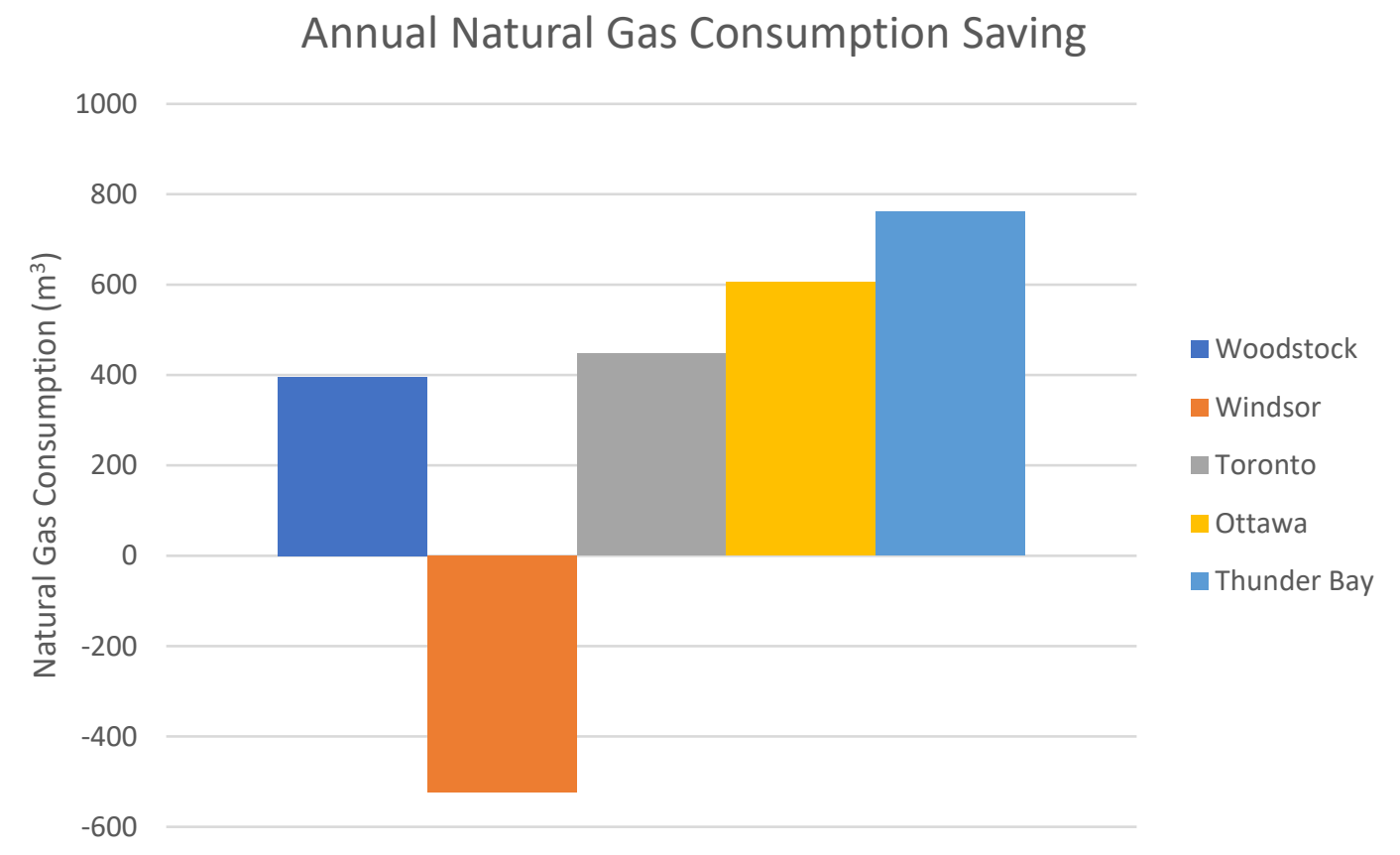

Figure 19: Comparison of annual natural gas consumption saving by using GEHP

Table 22. Annual natural gas consumption saving

\begin{tabular}{|l|c|}
\hline City & Annual Natural Gas Consumption Saving $\left(\mathrm{m}^{3}\right)$ \\
\hline Woodstock & 395 \\
\hline Windsor & -523 \\
\hline Toronto & 447 \\
\hline Ottawa & 605 \\
\hline Thunder Bay & 761 \\
\hline
\end{tabular}

Table 23. Annual electricity consumption saving

\begin{tabular}{|l|c|}
\hline City & Annual Electricity Consumption Saving (kWh) \\
\hline Woodstock & 7,549 \\
\hline Windsor & 9,670 \\
\hline Toronto & 8,580 \\
\hline Ottawa & 8,478 \\
\hline Thunder Bay & 7,314 \\
\hline
\end{tabular}




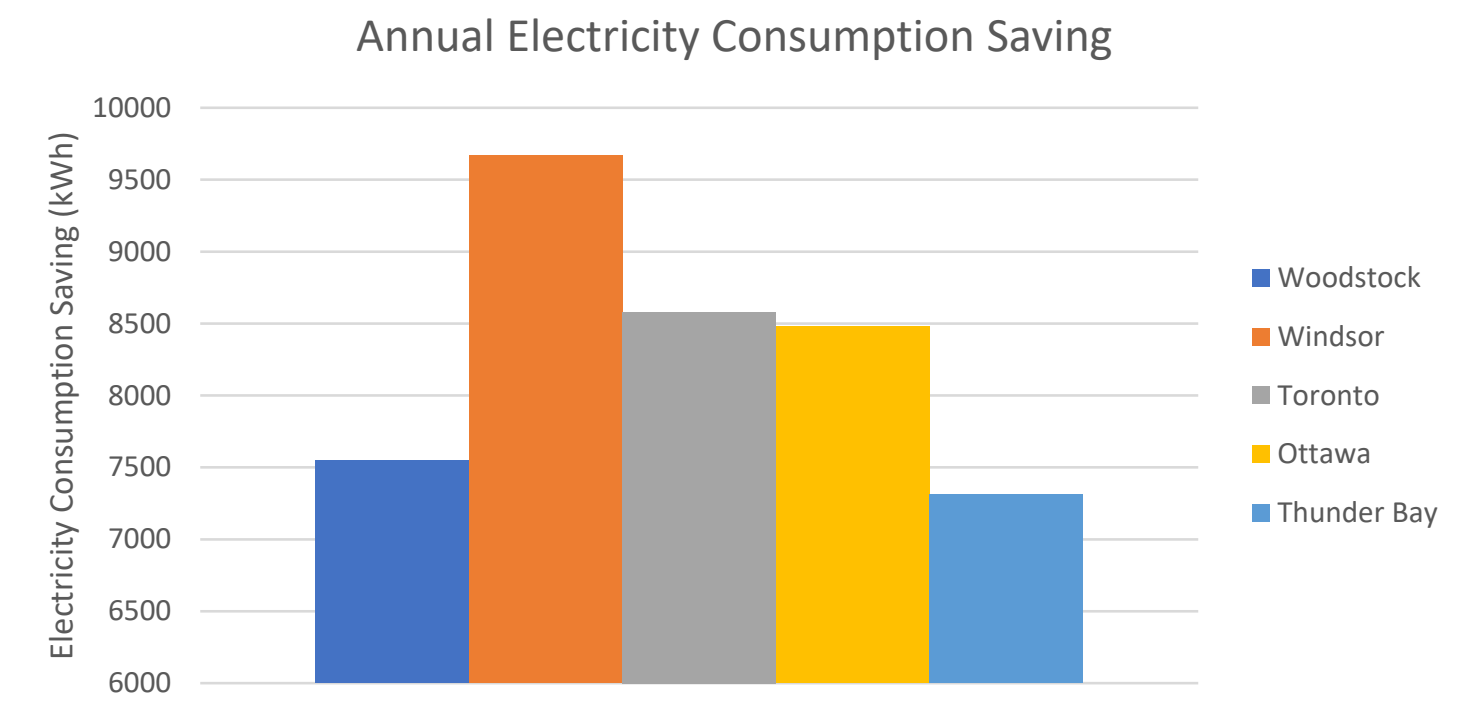

Figure 20: Comparison of annual electricity consumption saving by using GEHP

Total annual energy consumption saving is represented in Figure 21 and Table 24 shows the actual values. It could be seen that Thunder Bay has the highest potential for annual energy saving among all cities which is 62,401 MJ. Ottawa and Toronto stand in the second and third rank, and their total annual energy savings are 59,768 $\mathrm{MJ}$ and 53,973 $\mathrm{MJ}$, respectively. Windsor has the lowest possible total annual energy saving with a significant difference compared to the rest. The total annual energy saving for Windsor is 21,145 MJ.

Table 24. Annual energy consumption saving

\begin{tabular}{|l|c|}
\hline City & Annual Energy Consumption Saving (MJ) \\
\hline Woodstock & 48,520 \\
\hline Windsor & 21,145 \\
\hline Toronto & 53,973 \\
\hline Ottawa & 59,768 \\
\hline Thunder Bay & 62,401 \\
\hline
\end{tabular}

Cooling degree days (CDD) and heating degree days (HDD) for the cities are illustrated in Table 25. They are measurements to investigate energy demand of a building. The CDD is the number of degrees in which a day's average temperature is above $18^{\circ} \mathrm{C}$, therefore the building needs to be cooled. On the other hand, HDD is the number of degrees that a day's average temperature is 
below $18^{\circ} \mathrm{C}$ and the building requires to be heated. It could be concluded that Thunder Bay and Ottawa which have the highest HDD, perform greater annual energy consumption savings.

Table 25. Cooling and heating degree days

\begin{tabular}{|l|c|c|}
\hline \multicolumn{3}{|c|}{ Cooling and Heating Degree Days } \\
\hline City & CDD & HDD \\
\hline Woodstock & 308 & 4133 \\
\hline Windsor & 567 & 3561 \\
\hline Toronto & 516 & 3265 \\
\hline Ottawa & 372 & 4571 \\
\hline Thunder Bay & 86 & 5701 \\
\hline
\end{tabular}

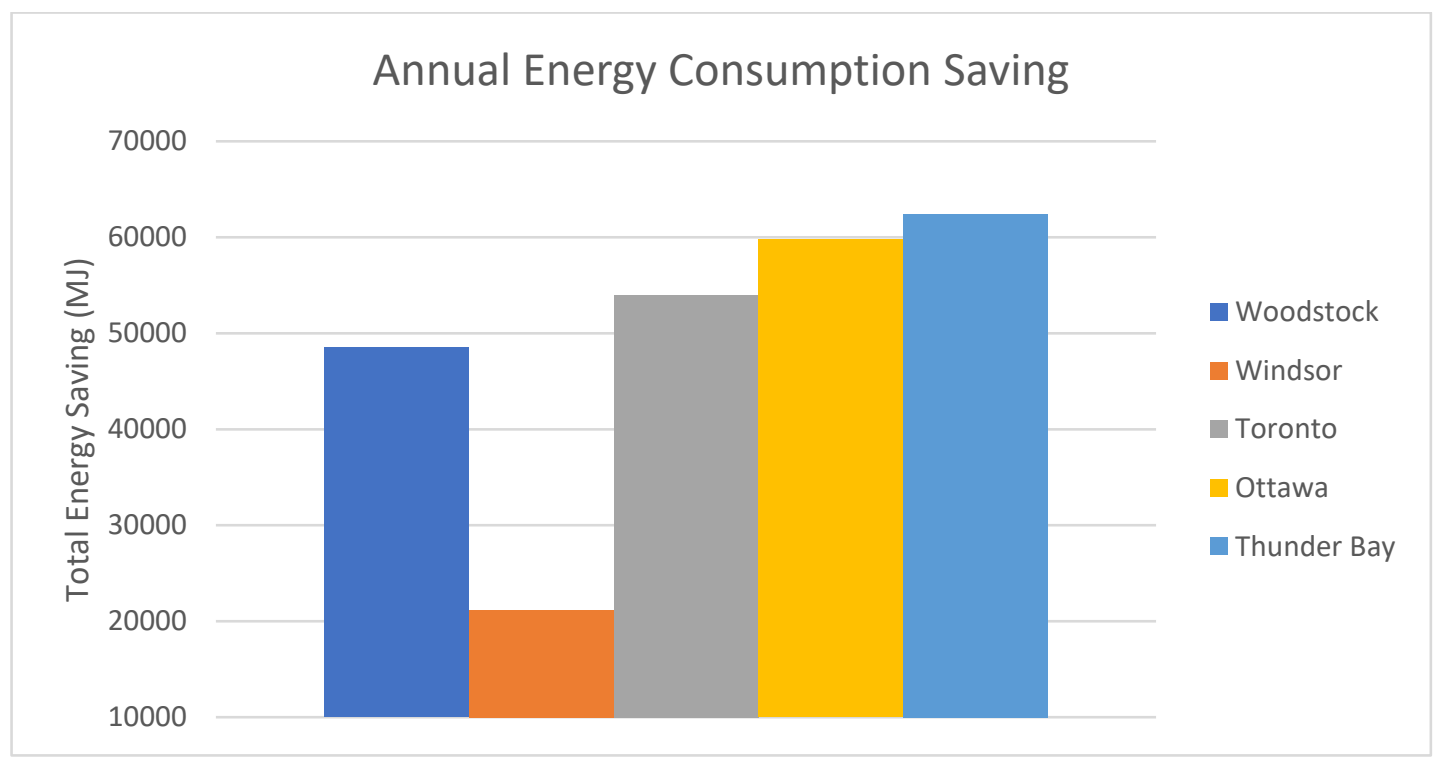

Figure 21: Comparison of annual energy consumption saving by using GEHP

Emission factors are the rate at which a pollutant is released into the atmosphere due to a process activity. Emission factors are expressed in kilograms $(\mathrm{kg})$ or metric tonnes $(\mathrm{t})$ of $\mathrm{GHG}$ emissions per unit of consumption activity [35]. Typically, the factors for a given category of activity for instance, building energy or fleet fuel consumption - are expressed in common units to enable comparison across different fuel types, travel modes, etc. Usually, emission factors are specified by individual gas. In some cases, a cumulative factor for multiple gases is provided in kilograms 
$(\mathrm{kg})$ or tonnes $(\mathrm{t})$ of $\mathrm{CO}_{2}$ equivalent $\left(\mathrm{CO}_{2} \mathrm{eq}\right)$ emissions. Overall, $\mathrm{CO}_{2} \mathrm{eq}$ is the standard unit for measuring and comparing emissions across GHGs of varying potency in the atmosphere.

For later calculation, the GHG emission intensity of $29 \mathrm{gCO}_{2} \mathrm{eq} / \mathrm{kWh}$ has been taken as the GHG emission factor for the electric energy consumption [36]. The GHG emission factor for the natural gas was taken as $1,863 \mathrm{~g} \mathrm{CO}_{2} \mathrm{eq} / \mathrm{m}^{3}$ (or $49.01 \mathrm{kgCO}_{2} / \mathrm{GJ}$ ) as reported in the guide line version 2017 for the Greenhouse Gas Emissions reporting on Section 4(1) of Ontario Regulation 452/09 [37].

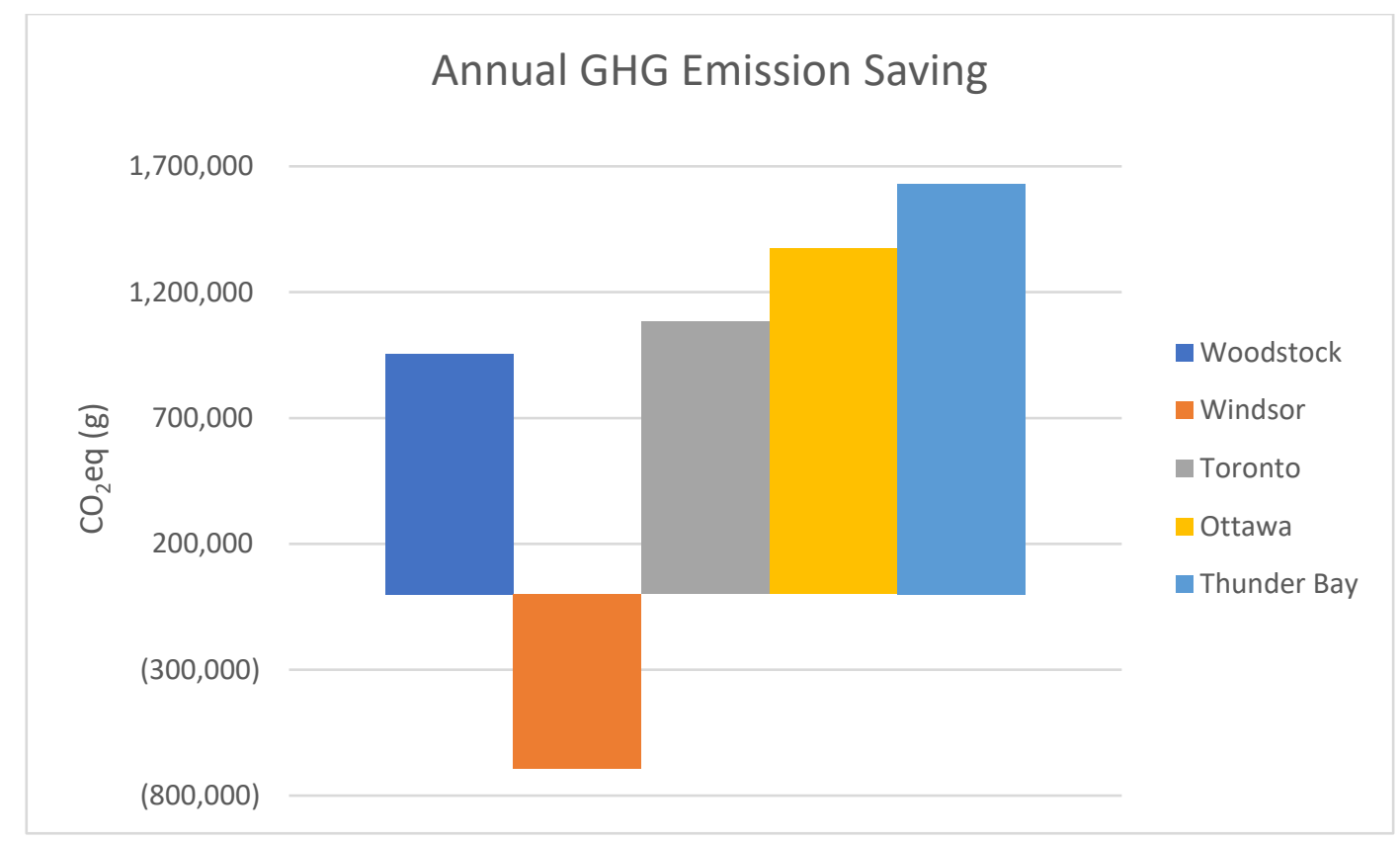

Figure 22: Comparison of annual GHG emission saving

Table 26. Annual GHG emission saving

\begin{tabular}{|l|c|}
\hline City & Annual GHG Emission Saving $\left(\mathrm{CO}_{2} \mathrm{eq}(\mathrm{g})\right)$ \\
\hline Woodstock & 955,149 \\
\hline Windsor & $-693,291$ \\
\hline Toronto & $1,082,156$ \\
\hline Ottawa & $1,373,689$ \\
\hline Thunder Bay & $1,630,730$ \\
\hline
\end{tabular}

The annual GHG emission saving $\left(\mathrm{CO}_{2} \mathrm{eq}(\mathrm{g})\right)$ from both natural gas and electricity consumptions is indicated in Figure 22 for replacing GEHP with RTU in the five cities and the values are shown in Table 26. Thunder Bay and Ottawa have the highest potential GHG emission 
saving at 1,630,730 and 1,373,689 $\mathrm{CO}_{2} \mathrm{eq}(\mathrm{g})$, respectively. Then, Toronto and Woodstock are the next cities with GHG emission saving at 1,082,156 and 955,149 $\mathrm{CO}_{2} \mathrm{eq}(\mathrm{g})$, respectively. As shown in Table 26, using GEHP in Windsor resulted in more annual GHG emission compared with RTU at $693,291 \mathrm{CO}_{2} \mathrm{eq}(\mathrm{g})$.

Marginal cost of electricity is the operating cost required to produce each $\mathrm{kWh}$ of electric energy. The marginal cost of electricity generation varies depending on the supply and demand for electricity, rising and falling by season, day and hour. In other words, the marginal cost varies with time of use (TOU) that fluctuates with time. The average marginal cost of electricity for the 2018 based on TOU Winter weekdays and Summer-week days is indicated in Table 27 for each city.

Table 27: Marginal cost of electricity for 2018 based on TOU

\begin{tabular}{|c|c|c|c|}
\hline \multicolumn{5}{|c|}{ Winter } \\
\hline & On-Peak $(\$ / \mathrm{kWh})$ & Mid-Peak $(\$ / \mathrm{kWh})$ & Off-Peak $(\$ / \mathrm{kWh})$ \\
\hline Woodstock & 0.19 & 0.13 & 0.09 \\
\hline Windsor & 0.17 & 0.12 & 0.08 \\
\hline Toronto & 0.19 & 0.14 & 0.09 \\
\hline Ottawa & 0.17 & 0.12 & 0.08 \\
\hline Thunder Bay & 0.16 & 0.1 & 0.07 \\
\hline \multicolumn{5}{|c|}{ Summer } \\
\hline Woodstock & 0.16 & 0.12 & 0.07 \\
\hline Windsor & 0.14 & 0.11 & 0.07 \\
\hline Toronto & 0.16 & 0.12 & 0.08 \\
\hline Ottawa & 0.14 & 0.1 & 0.07 \\
\hline Thunder Bay & 0.12 & 0.09 & 0.06 \\
\hline
\end{tabular}

The estimated marginal cost of Natural Gas based on the 2018 Enbridge commercial customer rate has been shown in Table 28 . 
Table 28: Marginal cost of Natural Gas

\begin{tabular}{|c|c|}
\hline & $\begin{array}{l}\text { Monthly rates }\left(\phi / \mathrm{m}^{3}\right) \text {, Depends on the range of the amount of } \\
\text { gas used monthly }\end{array}$ \\
\hline Marginal cost for Woodstock & $\begin{array}{l}23.16 \text { (for the first } 100 \mathrm{~m}^{3} \text { ) } \\
22.89 \text { (for the next } 150 \mathrm{~m}^{3} \text { ) } \\
22.21 \text { (for the next } 250 \mathrm{~m}^{3} \text { ) }\end{array}$ \\
\hline Marginal cost for Windsor & $\begin{array}{l}26.12 \text { (for the first } 30 \mathrm{~m}^{3} \text { ) } \\
26.03 \text { (for the next } 55 \mathrm{~m}^{3} \text { ) } \\
25.69 \text { (for the next } 85 \mathrm{~m}^{3} \text { ) } \\
25.31 \text { (for over } 170 \mathrm{~m}^{3} \text { ) }\end{array}$ \\
\hline Marginal cost for Toronto & $\begin{array}{l}26.99 \text { (for the first } 30 \mathrm{~m}^{3} \text { ) } \\
26.45 \text { (for the next } 55 \mathrm{~m}^{3} \text { ) } \\
26.01 \text { (for the next } 85 \mathrm{~m}^{3} \text { ) } \\
25.68 \text { (for over } 170 \mathrm{~m}^{3} \text { ) }\end{array}$ \\
\hline Marginal cost for Ottawa & $\begin{array}{l}25.91 \text { (for the first } 30 \mathrm{~m}^{3} \text { ) } \\
25.69 \text { (for the next } 55 \mathrm{~m}^{3} \text { ) } \\
25.21 \text { (for the next } 85 \mathrm{~m}^{3} \text { ) } \\
24.73 \text { (for over } 170 \mathrm{~m}^{3} \text { ) }\end{array}$ \\
\hline Marginal cost for Thunder Bay & $\begin{array}{l}24.12 \text { (for the first } 30 \mathrm{~m}^{3} \text { ) } \\
23.87 \text { (for the next } 55 \mathrm{~m}^{3} \text { ) } \\
23.54 \text { (for the next } 85 \mathrm{~m}^{3} \text { ) } \\
23.29 \text { (for over } 170 \mathrm{~m}^{3} \text { ) }\end{array}$ \\
\hline
\end{tabular}

Figure 23 indicates the total annual cost saving by using GEHP instead of RTU in the five cities and the values are shown in Table 29. Toronto and Ottawa have the highest annual cost savings at $\$ 1,411$ and $\$ 1,295$, respectively. In the next step, Woodstock and Windsor have the potential of annual cost savings at $\$ 1,200$ and $\$ 1,192$, respectively. The lowest annual cost saving is for Thunder Bay at $\$ 1,115$. 


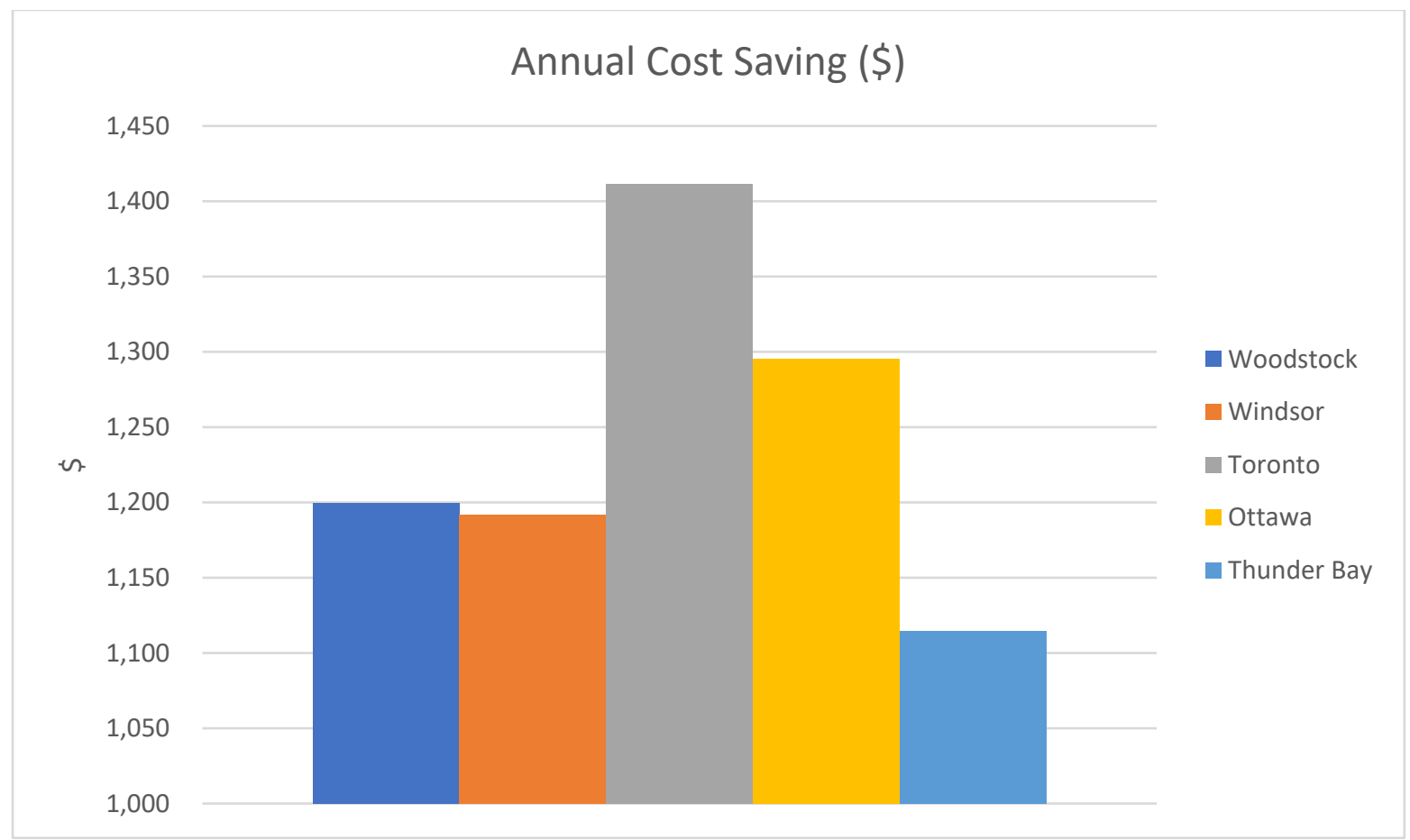

Figure 23: Total annual cost saving by using GEHP

Table 29. Annual cost saving

\begin{tabular}{|l|c|}
\hline City & Annual Cost Saving (\$) \\
\hline Woodstock & 1,200 \\
\hline Windsor & 1,192 \\
\hline Toronto & 1,411 \\
\hline Ottawa & 1,295 \\
\hline Thunder Bay & 1,115 \\
\hline
\end{tabular}




\section{Conclusion}

In this report, a case study of energy modeling for the GEHP that delivers heating and cooling energy to the office building located in Woodstock, Ontario, was conducted.

Blower door infiltration test was performed (by depressurizing the building) to determine the amount of infiltration of the building. The test result of the building leakage curve revealed that $4311 \mathrm{cfm}$ was the total airflow leakage at differential pressure of 50Pa which was equivalent to 6.63 ACH for the Woodstock office building volume.

Additionally, comparison was made between the eQUEST simulated energy consumption and regression analysis, which was obtained from measured data. The accuracy of the eQUEST simulation was verified by using building simulation criterion, ASHRAE Guideline 14-2002. The comparison between the simulated and regression analysis of both the gas and electricity consumption of GEHP and RTU are within the range of the ASHRAE calibration criteria.

The results of the simulation for Woodstock office building showed that the percentage of the difference of the total annual GEHP consumption of natural gas and electricity between the simulation and regression analysis were $4.02 \%$ and $3.91 \%$, respectively. On the other hand, the percentage of the total difference for the RTU annual natural gas and electricity consumption between the simulation and regression analysis were $1.38 \%$ and $3.43 \%$, respectively.

Furthermore, both GEHP and RTU simulation models were developed for four other major cities in Ontario; Toronto, Windsor, Ottawa and Thunder Bay. It was shown that Thunder Bay has the highest annual energy consumption and GHG savings at 62,401 kWh and 1,630,730 $\mathrm{CO}_{2} \mathrm{eq}(\mathrm{g})$, respectively, using GEHP, while Windsor has the lowest annual energy saving. It was also concluded that Toronto indicates the highest annual cost saving at \$1,411 since natural gas and electricity rates are higher in Toronto. In turn, saving energy consumption is more cost saving in Ontario compared with the other cities. Thunder Bay has the lowest annual cost saving using GEHP. Using GEHP in Windsor does not provide annual GHG saving and it generates more GHG than RTU. Overly using GEHP in Ontario could be beneficial in terms of annual cost, GHG and energy saving, however the performance of GEHP is different depending on the region that it is used. 


\section{Future Work and Potential Problems Faced in this Research Work}

As mentioned in the report, based on the available measured data by the consultant, regression analysis was performed to predict the natural gas and electricity consumption of RTU and GEHP. Besides, using the limited available information, eQUEST simulation analysis was conducted to estimate the energy consumed by RTU and GEHP. Great effort has been made in order to produce the simulation results. However, the team is not certain the quality of the provided data by the Woodstock office. For instance, there is a doubt whether the previously measured data of energy consumed by the RTU and GEHP are obtained from properly installed and calibrated instruments and sensors at the proper location of the system. There is no clearly stated information on the measured data on whether the electricity consumption is only for external unit or it includes both internal and external units. Moreover, though the team wants to know the maximum energy consumption corresponding to the maximum RPM of GEHP, there was no such information provided to the team.

In the near future, the team is interested and urges to redesign and install a more developed and enhanced data acquisition system so that the proper and reliable measured data will be used for the quality and in-depth research outcome of the GEHP system's capacity and performance. The team would like to have data for each component of the system in order to have a better understanding of the GEHP operating characteristics and performances particularly in the context of Ontario/Canada. As a result, the team seeks the full support and encouragement from the Union Gas Ltd. and Enbridge Gas Distribution for the progress research work on the GEHP. 


\section{References}

[1] Wongsuwan W, Kumar S, Neveu P, Meunier F. A review of chemical heat pump technology and applications. Appl Thermal Eng. 21(2001) 1489-519.

[2] Hepbasli A, Ozgener L. Development of geothermal energy utilization in Turkey: a review. Renewable Sustainable Energy Rev. 8(2004)433-60.

[3] Ozgener O, Hepbasli A. A review on the energy and exergy analysis of solar assisted heat pump systems. Renewable Sustainable Energy Rev. (2007)482-96.

[4] S. Sanaye, M.A. Meybodi, M. Chahartaghi, Modeling and economic analysis of gas engine heat pumps for residential and commercial buildings in various climate regions of Iran, Energy and Buildings .42 (2010) $1129-1138$.

[5] Huanwei Liu, Qiushu Zhou, Haibo Zhao. Experimental study on cooling performance and energy saving of gas engine-driven heat pump system with evaporative condenser. Energy Conversion and Management 123 (2016) 200-208.

[6] Behnaz Rezaie, Marc A. Rosen. District heating and cooling: Review of technology and potential enhancements. Applied Energy, 2012 (93)2-10.

[7] Y.G. Chen, Z. Yang, Theoretical simulation and experimental research on the system of air source energy independence driven by internal-combustion engine, Energy and Buildings. 43(2011) 1351-1358.

[8] Hepbasli A, Erbay Z, Icier F, Colak N, Hancioglu E. A review of gas engine driven heat pumps (GEHPs) for residential and industrial applications. Renew Sustain Energy Rev; 13(2009)85-99.

[9] J.Brenn.P.Soltic,C.Bach, Comparison of natural gas driven heat pumps and electrically driven heat pumps with conventional systems for building heating purposes, Energy and Buildings 42(2010)904-908.

[10] M.D. d'Accadia, Survey on GHP technology, Proceedings of the ASME Advanced Energy Systems Division 1 (1998) 313-323.

[11] D.D. Colosimo, Introduction to engine-driven heat pumps-Concepts, approach, and economics, ASHRAE Transactions 93 (Pt. 2) (1987) 987-996.

[12] Zhao Y, Shigang Z, Haibe Z. Optimization study of combined refrigeration cycles driven by an engine. Appl Energy 76 (2003)379-89. 
[13] Rajeev Kamal, Arun Kumar Narasimhan, Chatura Wickramaratne, Abhinav Bhardwaj, D. Yogi Goswami , Elias K. Stefanakos , Herbert A. Ingley. Field performance of gas-engine driven heat pumps in a commercial building. International journal of refrigeration 68 (2016) 15-27.

[14] E. Elgendy, J. Schmidt,A. Khalil, M. Fatouh. Performance of a gas engine heat pump (GEHP) using R410A for heating and cooling applications. Energy 35 (2010) 4941- 4948.

[15] E. Elgendy, J. Schmidt. Experimental study of gas engine driven air to water heat pump in cooling mode. Energy 35 (2010) 2461-2467.

[16] Feng-Guo Liu, Zhong-Yun Tian, Fu-Jiang Dong, Chao Yan, Rui Zhang, Ai-Bin Yan. Experimental study on the performance of a gas engine heat pump for heating and domestic hot water. Energy and Buildings 152 (2017) 273-278.

[17] Chen Yiguang, Yang Zhao,Wu Xi,Wang Mingtao,Liu Huanwei. Theoretical simulation and experimental research on the system of air source energy independence driven by internal combustion engine. Energy and Buildings 43 (2011) 1351-1358.

[18] Zhenjun $\mathrm{Xu}$, Zhao Yang. Saving energy in the heat-pump air conditioning system driven by gas engine. Energy and Buildings 41 (2009) 206-211.

[19] Xin Zhang, Zhao Yang, Xi Wu, Xiang-Chao Su. Evaluation method of gas engine-driven heat pump water heater under the working condition of summer. Energy and Buildings 77 (2014) 440444.

[20] MacArthur JW, Grald EW. Unsteady compressible two-phase flow model for predicting cyclic heat pump performance and a comparison with experimental data. International Journal of Refrigeration 12 (1989) 29-41.

[21] Rusk RP, Van Gerpen JN, Nelson RM, Pate MB. Development and use of a mathematical model of an engine-driven heat pump. ASHRAE Trans. Pt. 2 (1990)282-90.

[22] P. Welsby, S. Devotta, P.J. Diggory, Steady- and dynamic-state simulations of heat-pump. Part 1: literature review, Applied Energy 31 (1988) 189-203.

[23] R.R. Zhang, X.S. Lu, S.Z. Li, W.S. Lin, A.Z. Gu, Analysis on the heating performance of gas engine driven air to water heat pump based on a steady state model, Energy Conversion and Management 46 (2005) 1714-1730.

[24] Bin Hu, Cuichao Li, Xiang Yin, Feng Cao, Pengcheng Shu. Thermal modeling and experimental research of a gas engine-driven heat pump in a variable condition. Applied Thermal Engineering 123 (2017) 1504-1513. 
[25] Zhao Yang, Wen-Bin Wang, Xi Wu. Thermal modeling and operating tests for a gas-engine driven heat pump working as a water heater in winter. Energy and Buildings 58 (2013) 219-226. [26] E.Elgendy, J. Schmidt, A. Khalil, M. Fatouh. Modelling and validation of a gas engine heat pump working with R410A for cooling applications. Applied Energy 88 (2011) 4980-4988.

[27] Li S, Zhang W, Zhang R, Lv D, Huang Z. Cascade fuzzy control for gas engine driven heat pump. Energy Conversion and Management 46(2005)1757-66.

[28] Yang Z, Haibo Z, Zheng F. Modeling and dynamic control simulation of unitary gas engine heat pump. Energy Conversion and Management 48 (2007)3146-53.

[29] Shin Y, Yang H, Tae CS, Jang CY, Cho S. Dynamics modeling of a gas engine driven heat pump in cooling mode. Journal of Mechanical Science and Technology 20(2006)278-85.

[30] Xiaobing Liu, Tianzhen Hong. Comparison of energy efficiency between variable refrigerant flow systems and ground source heat pump systems. Energy and Buildings 42 (2010) 584-589.

[31] Yonghua Zhu, Xinqiao Jin, Zhimin Du, Bo Fan, Xing Fang. Simulation of variable refrigerant flow air conditioning system in heating mode combined with outdoor air processing unit. Energy and Buildings 68 (2014) 571-579.

[32] Tolga N. Aynur, Yunho Hwang, Reinhard Radermacher. Simulation comparison of VAV and VRF air conditioning systems in an existing building for the cooling season. Energy and Buildings 41 (2009) 1143-1150.

[33] R.Afify, Designing VRF systems, ASHRAE Journal 50(2008)52-55.

[34] ASHRAE, ANSI/ASHRAE Guideline 14-2002: Measurement of Energy and Demand Savings, ASHRAE, Atlanta, 2002.

[35] https:// weatherstats.ca/metrics/hdd.html

[36] Ministry of Environment. 2016. "2016/17 B.C. BEST PRACTICES METHODOLOGY FOR QUANTIFYING GREENHOUSE GAS EMISSIONS." http://www2.gov.bc.ca/assets/gov/ environment/ climatechange/ cng/methodology/2016-17-pso-methodology.pdf.

[37]www.ieso.ca /- /media/files/ IESO/ Document- Library /engage/ cf/ CF 20170427 collaboration. pdf?la=en

[38] Government of Ontario. 2016. "Guide: Greenhouse Gas Emission Reporting / Ontario.ca" 